\title{
Endogeneidade das Elasticidades-Renda nos Modelos de Crescimento com Restrição Externa: uma Resenha ${ }^{1}$
}

Fabrício Míssio*

\begin{abstract}
Resumo
O objetivo do artigo é fazer uma revisão dos fundamentos e dos desenvolvimentos recentes sobre a hipótese de endogeneidade das elasticidades-renda do comércio internacional dentro da abordagem dos modelos de crescimento com restrição do balanço de pagamentos. Enfatizam-se os trabalhos que admitem essa endogeneidade em relação ao nível da taxa real de câmbio e que se complementam ao utilizarem estruturas formais semelhantes. Os principais resultados mostram a importância das elasticidades setoriais, do efeito composição e do câmbio real como instrumento estratégico para o desenvolvimento econômico.
\end{abstract}

Palavras-chave: Crescimento, Restrição externa e câmbio real

\begin{abstract}
The aim of this paper is to review the fundamentals and recent developments about of balance of payments constrained growth models. More specifically the emphasis is in the works that admit the hypothesis that the income elasticity of the demand for exports and imports is endogenous to the level of the real exchange and that are complementary to the formal structures. The main results show the importance of the sectoral elasticities and the composition effect and emphasize the real exchange rate as a strategic tool for economic development.
\end{abstract}

Keywords: Growth, external constrained growth and real exchange rate.

JEL Classification: 011; 033; 041

\footnotetext{
${ }^{1} \mathrm{O}$ autor agradece os comentários recebidos do parecerista anônimo desta revista. Evidentemente, erros e omissões remanescentes são de responsabilidade do autor.

* Professor do Programa de Pós Graduação em Desenvolvimento Regional e Sistemas Produtivos (PPGDRS/UEMS).
} 


\section{Introdução}

A ênfase de Kaldor na evolução das exportações como o principal componente da demanda final levou autores como Thirwall (1979), McCombie e Thirwall (1994), entre outros, a formalizar suas ideias com base no "multiplicador do comércio internacional de Harrod", cuja demonstração conduz à conclusão de que a taxa de crescimento da economia é determinada pela taxa de crescimento das exportações e pela elasticidade-renda da demanda por importações (modelos de crescimento com restrição do balanço de pagamentos) ${ }^{2}$.

O benchmark dessa tradição é, portanto, o modelo de Thirlwall $(1979)^{3}$, segundo 0 qual o crescimento econômico de longo prazo pode ser explicado pelas condições de demanda - que determina uma restrição externa ao crescimento, ou seja, nenhum país pode crescer no longo prazo a uma taxa superior àquela que equilibra o seu balanço de pagamentos - e por questões estruturais, que se refletem nas elasticidades-renda da demanda por importações e exportações, responsáveis pela definição desta taxa de crescimento. Essas questões estruturais estão associadas, em grande parte, ao progresso tecnológico e à forma de inserção externa dos países em desenvolvimento, como nas interpretações de Presbisch (1949) e Fajnzylber (1983, 2000), entre outros.

Formalmente, o referido modelo pode ser descrito pelas seguintes Equações:

$$
\begin{aligned}
& P_{d} \cdot X=P_{f} \cdot M \cdot E \\
& M=\left(P_{f} \cdot E\right)^{\psi} \cdot P_{d}^{\phi} \cdot Y^{\pi} \\
& X=\left(P_{d} / E\right)^{\eta} \cdot P_{f}^{\delta} \cdot Z^{\varepsilon}
\end{aligned}
$$

em que $P_{d}$ é o preço doméstico; $X$ são as exportações; $P_{f}$ é o preço externo; $E$ é a taxa de câmbio nominal; $M$ são as importações; $Y$ é a renda interna; $\psi$ é a elasticidade preço das importações $(\psi<0) ; \phi$ é a elasticidade-preço cruzada $(\phi>0) ; \pi$ é a elasticidade-renda das importações $(\pi>0)$; $\eta$ é a elasticidade- preço das exportações $(\eta<0) ; \delta$ é a elasticidadepreço cruzada $(\delta>0) ; \varepsilon$ é a elasticidade-renda das exportações $(\varepsilon>0)$; e $Z$ é a renda externa ${ }^{4}$. A Equação (1) representa a condição de equilíbrio do Balanço Comercial, enquanto a (2) e (3) representam as funções demanda por importações e exportações, respectivamente.

Reescrevendo as equações em termos dinâmicos e fazendo algumas manipulações algébricas, é possível resolver esse sistema para a taxa de crescimento da renda doméstica compatível com o equilíbrio no Balanço de Pagamentos (BOP), $y$;

$$
y=\left[(1+\eta+\psi)\left(p_{d t}-p_{f}-e\right)+\varepsilon \cdot(z)\right] / \pi
$$

\footnotetext{
${ }^{2}$ Convém ressaltar que o modelo export led é mais amplo dos que os modelos de crescimento com restrição externa, entendido esses como um desdobramento particular do primeiro.Ademais, embora se estabeleça algumas conexões entre aspectos dessas várias contribuições, onde se enfatiza possíveis relações de complementaridade, há de se destacar também a existência de aspectos que estabelecem relações de conflito entre concepções específicas, formas de modelagem matemática ou estratégias de estimação empírica (ver Anexo 1). Por exemplo, a hipótese de endogeneidade das elasticidades renda pode suscitar a necessidade de reformulação dos testes econométricos, uma vez que tal hipótese pode introduzir o problema do viés de endogeneidade nas estimativas.

${ }^{3}$ Segundo Cimoli, Porcile e Rovira (2010, p. 390), "The BOP-constrained growth model can be used to capture key economic insights of both the Keynesian and strucuturalist traditions in economic theory."

${ }^{4}$ As variáveis, quando escritas em letras minúsculas, simbolizam taxa de crescimento, salvo quando contrariamente especificado.
} 
Considerando a hipótese de que os preços relativos medidos em termos de moeda comum permanecem inalterados no longo prazo $\left(p_{d}=p_{f}+e\right)$, então é possível simplificar a Equação (4), obtendo a denominada Lei de Thirlwall:

$$
y=\varepsilon . z / \pi=x / \pi
$$

ou seja, a taxa de crescimento compatível com equilíbrio no BOP é igual à razão entre a taxa de crescimento das exportações e a elasticidade-renda da demanda por importações.

Existe uma série de desdobramentos teóricos e empíricos que exploram diferentes pontos dentro dessa abordagem. Entre as contribuições teóricas, pode-se destacar Elliot e Rhodd (1999), que incorporam o endividamento externo e seu serviço ao modelo elaborado em Thirlwall e Hussain (1982), enquanto Moreno-Brid (2003) incorpora o serviço de juros da dívida externa ${ }^{5}$. Empiricamente, essa abordagem tem sido validada por uma variedade de evidências para diversos países (Thirlwall e Hussain, 1982; Lopez e Cruz, 2000; Bértola, Higachi e Porcile, 2002; Jayme Jr., 2003 e 2007; Holland, Vieira e Canuto, 2004; Carvalho e Lima, 2009; Cimoli, Porcile e Rovira, 2010; entre outros).

Não obstante, um dos principais desdobramentos dessa abordagem é a lei multissetorial de Thirwall desenvolvida por Araújo e Lima (2007). Os autores derivam uma taxa de crescimento com equilíbrio no BOP análoga à lei de Thirlwall de uma estrutura macrodinâmica multissetorial pasinettiana. 0 resultado mostra que a taxa de crescimento da renda per capita de um país é diretamente proporcional à taxa de crescimento de suas exportações, com tal proporcionalidade existente inversamente (diretamente) relacionada à elasticidade setorial da demanda por importações (exportações). Essas elasticidades são ponderadas pelos coeficientes que medem a participação de cada setor no total das importações e exportações, respectivamente. $\mathrm{como}^{6}$

A versão multissetorial da taxa de crescimento com equilíbrio no BOP pode ser escrita

$$
\sigma_{y}^{U}=\frac{\sum_{i=1}^{n-1} \xi \beta_{i} a_{i \hat{n}} a_{n i}}{\sum_{i=1}^{n-1} \phi_{i} a_{\hat{i n}} a_{n i}\left(\sum_{i=1}^{n-1} \beta_{i}\right)} \sum_{i=1}^{n-1} \frac{\dot{a}_{i \hat{n}}}{a_{i \hat{n}}}
$$

em que $\sigma_{y}^{U}=y_{U} / y_{U}$ é a taxa de crescimento da renda do país $U ; a_{i \hat{n}}$ representa o coeficiente de demanda externa per capita da commodity final $i$, com $i=1,2, \ldots, n-1$; $a_{i n}$ é o coeficiente de demanda por importações de commodities per capita $i$ produzido no país A. 0 coeficiente de produção dos bens de consumo é dado por $a_{n i}$, que representa a quantidade de trabalho empregada em cada setor. 0 setor das famílias no país A é definido por $\hat{n}$, e o tamanho da população em cada país relaciona-se com o outro país através do coeficiente de

\footnotetext{
${ }^{5}$ Nesses modelos, o que muda é a definição formal de restrição externa, permitindo chegar a resultados diferentes a partir de sofisticações analíticas.

${ }^{6}$ Assume-se uma versão do modelo (pasinettiano) sem bens de capital para empreender a análise do crescimento com restrição no BOP em uma economia multissetorial no qual a demanda varia ao longo do tempo a uma taxa particular em cada um dos setores dos dois países: Defina-se A, o país avançado e, $\mathrm{U}$, o país menos desenvolvido. Assume-se, também, que ambos os países produzem $\mathrm{n}$-i bens de consumo: um em cada setor verticalmente integrado, mas com diferentes padrões de produção e consumo.
} 
proporcionalidade $\xi \cdot \beta_{i}\left(\phi_{i}\right)$ é a elasticidade- renda da demanda por exportações (importações).

A Equação (6) mostra que a taxa de crescimento da renda per capita no país U é diretamente proporcional à taxa de crescimento de suas exportações (segundo termo do lado direito da equação) e que o país vai se beneficiar mais do crescimento da demanda externa e, assim, experimentar altas de crescimento que são consistentes com o equilíbrio do BOP, quanto menor (maior) for a elasticidade-renda setorial da demanda por importações (exportações).

Ressalta-se que as elasticidades-rendas setoriais são ponderadas pelos coeficientes que medem a participação de cada setor no total do volume exportado e importado. Assim, mesmo se elas permanecem constantes, a mudança na taxa de crescimento total pode ser ocasionada por mudanças estruturais originadas da evolução dos gostos ou das preferências de acordo com a lei de Engel's. Logo, a principal implicação do modelo multissetorial é que mudanças na composição da demanda, que não se refletem em mudanças nas elasticidades, mas advêm de mudanças na participação de cada setor na exportação ou importação agregada, também importam para 0 crescimento econômico ${ }^{7}$.

Em resumo, o crescimento nos modelos com equilíbrio no Balanço de Pagamentos (BPCG) depende das elasticidades-renda do comércio e da composição setorial da economia ${ }^{8}$. Desenvolvimentos recentes têm avançado nessas duas questões. Por um lado, uma série de trabalhos tem explorado a questão da endogeneidade das elasticidades-renda e, por outro, 0 efeito composição, ou seja, a ideia de que a composição setorial da economia importa e que mudanças em direção a setores com maior elasticidade-renda da demanda por exportações são favoráveis ao crescimento. Em comum, esses trabalhos têm apontado para a importância do nível da taxa real de câmbio como instrumento capaz de induzir a mudança estrutural e promover alterações pró-crescimento.

Nesse contexto, o objetivo desse artigo é fazer uma revisão dos fundamentos e dos desenvolvimentos recentes desta literatura que incorporam a hipótese de endogeneidade das elasticidades-renda da demanda por importações e exportações e do efeito composição. M ais especificamente, serão retomados os trabalhos que propuseram esses desdobramentos, enfatizando-se as justificativas teóricas e a forma analítica em que eles são apresentados na literatura. Para tanto, os argumentos teóricos são apresentados juntamente com uma síntese da estrutura analítica formal, o que facilita o entendimento e permite mostrar como essa análise é capaz de dialogar com outras abordagens. Em geral, essa literatura incorpora esses argumentos propondo alterações nas Equações (5) e (6) ${ }^{9}$.

\footnotetext{
${ }^{7}$ Gouvêa e Lima (2010) estimam a Lei de Thirlwall Multissetorial para oito países no período de 1962 2006, demonstrando que ela não é rejeitada para nenhum dos países. Em outros termos, a composição setorial das exportações e importações é importante para o crescimento. Para o caso brasileiro ver Queiroz et al. (2011) e Soares e Teixeira (2012).

${ }^{8}$ Observe que, de acordo com os modelos BPCG, diferenças nas elasticidades entre os países têm como consequência distintos graus de restrição externa ao crescimento econômico. A questão fundamental torna-se, portanto, entender os determinantes dessas elasticidades. Conforme Resende e Torres (2008), a literatura que segue o modelo benchmark de Thirlwall (1979) não tem uma explicação consistente para o fato da demanda (o grau de atração) dos bens produzidos nos países em desenvolvimento - que já completaram seu processo de industrialização - ser menor do que aqueles produzidos nos países desenvolvidos. Assim, em partes, a hipótese de endogeneidade das elasticidades renda do comércio exterior surge como resultado dessa problemática.

${ }^{9}$ Não é objetivo esgotar toda a literatura existente sobre o tema, sendo que a ênfase recai sobre os desenvolvimentos que se complementam teórica e formalmente. Como o tema é pauta de discussão,
} 
Antes de prosseguir, cabe ressaltar que no plano empírico, a "lei de Thirlwall" tem sido submetida a diversos testes que tentam captar diferentes aspectos com vistas a uma avaliação do seu poder explicativo. Esses testes podem ser divididos em dois "momentos": no primeiro, a discussão entrou-se na identificação de formas de realização do teste empírico e, no segundo, na técnica econométrica mais adequada (inclusão de dummies, quebra de séries, suavização de séries, escolha das variáveis relevantes, entendimento da dinâmica de ajustamento de longo e curto prazo, etc.) (Ver anexo 2). Em geral, as evidências indicam que essa abordagem tem sido validada por uma variedade de evidências para diversos países. Não obstante, são incipientes (na verdade, em grande parte ainda inexistentes) os trabalhos que buscam testar empiricamente a hipótese de endogeneidade das elasticidades e do efeito composição (até porque essas análises são recentes). Assim, para os propósitos desse trabalho (e por uma questão de limitação da própria literatura), a ênfase recai nos desdobramentos teóricos correntes dentro dessa abordagem.

Para cumprir com o objetivo, este trabalho encontra-se dividido em cinco seções, além desta introdução e das considerações finais. Na seção 2, recuperam-se aqueles trabalhos precursores em propor a hipótese de endogeneidade das elasticidades; na seção seguinte, destacam-se os que enfatizam o efeito composição e o papel da taxa real de câmbio. Na seção 4, apresentam-se os trabalhos que destacam os efeitos do câmbio real sobre a heterogeneidade produtiva e o progresso tecnológico e, portanto, a consequente endogeneidade das elasticidades; na seção seguinte, apresentam-se duas abordagens que integram a referida hipótese nos modelos norte-sul; e, por fim, é apresentado o trabalho que estende a lei multissetorial de Thirlwall.

\section{A Endogeneidade das Elasticidades: Precursores}

Um dos trabalhos pioneiros a propor a hipótese de endogeneidade das elasticidades-renda do comércio exterior no modelo benchmark de Thirwall foi Palley (2002). Segundo o autor, a falha de incorporar o lado da oferta da economia na estrutura dos BPCG origina uma incoerência interna dado que, no longo prazo, o crescimento não é limitado somente pela exigência de equilíbrio em conta corrente, mas também a taxa de crescimento do produto real tem de ser igual à taxa de crescimento da capacidade produtiva. Segundo o autor, esta inconsistência pode ser resolvida ao fazer a elasticidade-renda da demanda por importações ser uma função negativa do excesso de capacidade. A justificativa para tal procedimento é 0 fato de as importações estarem relacionadas aos "gargalos" da economia. À medida que o excesso de capacidade e o desemprego diminuem, esses "gargalos" se tornam mais relevantes e a participação das importações no incremento da renda aumenta.

Formalmente, a equação que descreve a taxa de crescimento da demanda por importações é dada por;

$$
m=\pi(u) y
$$

em que $u$ é a razão entre o produto corrente e o nível normal da capacidade do produto.

Com essa hipótese, o autor mostra que a taxa de crescimento do produto real será determinada pela exigência de que o crescimento da demanda tem de ser igual à taxa de

muitos trabalhos recentes têm abordado a questão da endogeneidade das elasticidades renda sob diferentes aspectos. Evidentemente, uma revisão detalhada de todos esses aspectos foge ao escopo deste trabalho. 
crescimento da capacidade produtiva. A restrição do BOP vai, então, determinar o nível de excesso de capacidade, dada a taxa de crescimento do produto real ${ }^{10}$.

Por outro lado, M cCombie e Roberts (2002) incorporam a mudança estrutural à lei de Thirwall por meio da introdução de histerese nos parâmetros que determinam a taxa de longo prazo da economia. Nesse caso, a elasticidade-renda da demanda é especificada como função não linear das taxas de crescimento passada. Formalmente,

$$
(\varepsilon / \pi)_{t}=\gamma_{1}+\gamma_{2}\left(\phi-y_{t-1}\right) y_{t-1} \quad \gamma_{1}, \gamma_{2}>0
$$

em que $\gamma_{1}, \gamma_{2}$ e $\phi$ são constantes e $y_{t-1}$ é o produto defasado.

A justificativa advém do entendimento de que elevadas taxas de crescimento passadas provavelmente têm um impacto negativo sobre a elasticidade-renda da demanda por exportações, uma vez que, para que um país seja bem sucedido no mercado internacional, ele tem que acompanhar, ao longo do tempo, o movimento da demanda internacional em uma hierarquia de bens (lei de Engel). Porém o sucesso desse processo necessita de uma capacidade de adaptação contínua da estrutura produtiva, o que poderia ser inviabilizado por taxas de crescimento prévias elevadas, uma vez que estas tendem a induzir o lock-in dessa estrutura que, consequentemente, se tornaria defasada com o passar do tempo. Por outro lado, taxas de crescimento extremamente baixas devem ter um impacto positivo sobre a elasticidade na medida em que um desempenho econômico não satisfatório pode gerar pressões por reformas estruturais. Tais pressões podem surgir em dois níveis: i) no nível político, em decorrência da insatisfação do eleitorado com as baixas taxas de crescimento e, consequentemente, dos elevados níveis de desemprego e baixos ganhos de salário real que tendem a acompanhá-las; ii) no próprio nível da produção, quando os detentores do capital tornam-se insatisfeitos com as baixas taxas de retorno de seus investimentos.

\section{Efeito Composição e Taxa Real de Câmbio nos Modelos BPCG}

Um dos trabalhos pioneiros que destaca o papel do nível da taxa real de câmbio dentro da literatura dos modelos de BPCG é o de Barbosa-Filho (2006). 0 autor analisa o funcionamento da restrição externa sobre as economias em desenvolvimento, com ênfase especial para a ligação entre as metas de inflação, a dinâmica da taxa real de câmbio e o crescimento no curto e no longo prazo. A principal conclusão é que a taxa de câmbio real pode ser um instrumento importante para promover 0 crescimento e desenvolvimento através de mudanças temporárias, mas, suficientemente longas no preço relativo entre bens comercializáveis e não comercializáveis.

0 autor destaca que, nos modelos a la Thirwall (1979), as elasticidades dos fluxos de comércio são constante durante o período em análise, tal que a renda e a taxa real de câmbio do país de origem se ajustam às condições internacionais. Esta hipótese não é muito forte para uma análise de curto prazo, mas é problemática para considerações de longo prazo. A razão é simples e intuitiva, pois, quanto mais longo o período sob análise, maior a probabilidade de que a estrutura de comércio do país doméstico se altere, especialmente se a operação da restrição externa ocorrer através de crises cambiais e grandes flutuações de renda. Ademais, 0 autor ressalta que há um ponto importante ignorado pelos modelos BPCG, qual seja, o nível da

\footnotetext{
${ }^{10}$ Oreiro (2016) mostra que a condição proposta por Palley (1996) não é suficiente para eliminar o problema de sobredeterminação na estrutura dos modelos BPCG, já que falha em distinguir taxa desejada de taxa natural de crescimento. A condição suficiente, segundo o autor, é introduzir o nível da taxa real de câmbio nessa estrutura.
} 
taxa real de câmbio pode ser um determinante importante do preço e das elasticidades-renda dos fluxos comerciais.

Em outras palavras, mesmo se as variações na taxa real de câmbio forem zero, no longo prazo, o seu nível pode ser importante porque afeta o preço relativo entre a produção nacional de bens comercializáveis e não comercializáveis e, desta forma, pode afetar a estrutura e a taxa de crescimento da economia ${ }^{11}$. Isso implica que é razoável assumir que 0 nível da taxa real de câmbio provavelmente altera as elasticidades das exportações e das importações. Ou seja, por exemplo, através da correta gestão da taxa de câmbio, é possível aliviar a restrição do BOP, aumentando (diminuindo) a elasticidade-renda das exportações (importações) domésticas. Em síntese, ainda que não explicitamente, o autor introduz a noção de endogeneidade das elasticidades em relação ao nível da taxa real de câmbio.

Ferrari, Freitas e Barbosa-Filho (2013) propõem um modelo de restrição externa com elasticidades endógenas ao nível da taxa real de câmbio. Nesse caso, as elasticidades se modificam no decorrer do tempo devido ao efeito composição ${ }^{12}$. 0 argumento é de que a manutenção da taxa de câmbio em um nível estável e competitivo altera as elasticidades no longo prazo num sentido que melhore a posição de comércio de um país em relação ao resto do mundo.

A hipótese fundamental do modelo é que a relação expressa pela Equação (5) se altera no longo prazo, pois as elasticidades mudam em função do efeito composição. Os efeitos do câmbio real sobre a demanda agregada no curto prazo perduram no longo prazo a favor do desenvolvimento econômico quando seu nível é mantido num patamar estável e competitivo por tempo suficiente para endogeneizar, nas elasticidades-renda, os efeitos benéficos do aumento das exportações, o que implica uma mudança na estrutura produtiva a favor dos bens tradables.

Formalmente, os autores admitem que a elasticidade-renda das importações é determinada da seguinte forma:

$$
\pi=\sum_{i=1}^{k} \omega_{i} \pi_{i}
$$

A pauta de importações de um país é composta por $k$ bens, sendo que cada bem possui uma elasticidade-renda específica $\pi_{i}$, cuja contribuição na determinação de $\pi$ depende de sua participação em tal pauta, $\omega_{i}$. Uma mudança no nível da taxa real de câmbio e a manutenção de sua estabilidade no longo prazo provocam uma alteração de $\pi$ por dois canais: a quantidade $k$ de bens que compõem a pauta de importações e o peso relativo de cada bem, $\omega_{i}$. Por exemplo, a manutenção do nível da taxa de câmbio real depreciado e competitivo diminui a variedade de bens importados e concentra a pauta naqueles bens essenciais ao funcionamento da economia. Todavia, o avanço no processo de desenvolvimento que essa política cambial proporciona implica a redução gradativa da necessidade de tais bens,

\footnotetext{
${ }^{11}$ Deve notar-se que, embora a taxa de câmbio real possa, de fato, ser estacionária no longo prazo (como defendido pelo mainstream), o curto prazo pode ser longo o suficiente para promover mudanças estruturais. Em outras palavras, a gestão temporária das taxas de câmbio para promover 0 desenvolvimento do setor transacionável pode ser suficiente para alterar a restrição do BOP permanentemente de forma favorável ou desfavorável.

${ }^{12} \mathrm{O}$ efeito composição refere-se à mudança das elasticidades provocada pela alteração na pauta de exportações e importações de um determinado país, no que diz respeito tanto à quantidade de bens quanto à participação relativa de cada um deles (Ferrari, Freitas e Barbosa-Filho, 2013, p. 03).
} 
pois eles passam a ser produzidos internamente para atender ao mercado doméstico e buscar sua inserção competitiva nos mercados externos. categorias $^{13}$ :

Para simplificar, os autores dividem as exportações e importações em duas

$$
\begin{aligned}
& X=X_{H T}+X_{L T} \\
& M=M_{H T}+M_{L T}
\end{aligned}
$$

A Equação (10) representa as exportações $(X)$, que são divididas em bens high tech $X_{H T}$ e bens low tech $X_{L T}$, assim como as importações $(M)$. Em termos de taxa de crescimento, tem-se que:

$$
\begin{aligned}
& x=\phi x_{H T}+(1-\phi) x_{L T} \quad \therefore 0<\phi<1 \\
& m=\lambda m_{H T}+(1-\lambda) m_{L T} \therefore 0<\lambda<1
\end{aligned}
$$

em que $\phi=X_{H T} / X$ e $\lambda=M_{H T} / M$. abaixo:

As exportações e importações de bens high tech e low tech são definidas conforme

$$
\begin{aligned}
& X_{H T}=a_{1} \theta^{\eta_{H T}} Z^{\varepsilon_{H T}} \\
& X_{L T}=a_{2} \theta^{\eta_{L T}} Z^{\varepsilon_{L T}} \\
& M_{H T}=a_{1} \theta^{-\psi_{H T}} Z^{\pi_{H T}} \\
& M_{L T}=a_{1} \theta^{-\psi_{L T}} Z^{\pi_{L T}}
\end{aligned}
$$

Nas Equações (14)-(17), $\theta$ é a taxa real de câmbio, $a_{1}, a_{2}, b_{1}$ e $b_{2}$ são as constantes das funções e cada categoria de bem possui elasticidades específicas representadas por parâmetros positivos. Colocando as referidas equações em termos de taxas de crescimento e substituindo em (12) e (13), temos;

$$
\begin{aligned}
& x=\left[\phi \eta_{H T}+(1-\phi) \eta_{L T}\right] e_{r}+\left[\phi \varepsilon_{H T}+(1-\phi) \varepsilon_{L T}\right] z \\
& m=-\left[\lambda \psi_{H T}+(1-\lambda) \psi_{L T}\right] e_{r}+\left[\lambda \pi_{H T}+(1-\lambda) \pi_{L T}\right]
\end{aligned}
$$

0 efeito composição se manifesta a partir da participação dos bens high tech na pauta de exportações e importações. Considerando a existência de apenas dois bens, 0 modelo torna-se mais complexo, pois passa a contar com oito elasticidades específicas. Nesse caso, os autores supõem que as elasticidades específicas $\left(\eta_{H T}, \eta_{L T}, \varepsilon_{H T}, \varepsilon_{L T}, \psi_{H T}, \psi_{L T}, \pi_{H T}\right.$ e $\left.\pi_{L T}\right)$ sejam dadas e que as elasticidades agregadas preço e renda das exportações e importações $(\eta, \varepsilon, \psi$ e $\pi$ ) sejam modificadas de acordo com a composição das pautas de exportações e importações.

Logo, os incentivos criados a favor dos tradeables high tech numa economia em desenvolvimento alteram as relações estruturais de comércio de um país com o resto do mundo, mudando tanto a pauta de exportações quanto a de importações em função das externalidades positivas sobre a estrutura produtiva doméstica proveniente do aumento das

\footnotetext{
${ }^{13}$ Para captar o efeito composição, é necessário que as exportações e/ou as importações sejam compostas por no mínimo dois bens (ou categorias de bens).
} 
exportações. Contudo, analisar as mudanças em cada uma delas pode trazer complicações desnecessárias. Assim, utilizam-se os parâmetros $\phi$ e $\lambda$ como indicadores das mudanças nas elasticidades agregadas.

Considerando que seja razoável supor que os bens high tech sejam mais ineslásticospreço $\left(\eta_{H T}<\eta_{L T}\right.$ e $\left.\psi_{H T}<\psi_{L T}\right)$ e mais elásticos-renda $\left(\varepsilon_{H T}>\varepsilon_{L T}\right.$ e $\left.\pi_{H T}>\pi_{L T}\right)$ do que os bens low tech, o comportamento das elasticidades pode ser estudado a partir de $\phi$ e $\lambda$. Quanto maior $\phi$, mais elástico-renda (maior $\varepsilon$ ) e mais inelástico-preço (menor $\eta$ ) serão as exportações. Quanto menor $\lambda$, mais ineslástico-renda (menor $\pi$ ) e mais elástico-preço (maior $\psi$ ) serão as importações. Portanto, 0 aumento de $\phi$ e a redução de $\lambda$ ao longo do tempo indicam uma melhora estrutural da relação de comércio de um país com o resto do mundo (Ferrari, Freitas e Barbosa-Filho, 2013).

Por fim, os autores chamam a atenção para outra hipótese fundamental referente à especificação de $\phi$ e $\lambda$ e à definição de seus argumentos. Por se tratar de razões que envolvem um componente fortemente tecnológico é razoável supor que as mesmas possuem uma relação na forma da função logística com o nível da taxa real de câmbio, considerando que 0 aumento da razão $\phi / \lambda$ represente melhorias no nível de desenvolvimento econômico. Assim, inicialmente, um aumento no nível da taxa real de câmbio permitirá a introdução de inovações tecnológicas e sua difusão motivada pelas externalidades ligadas às exportações, 0 que acontece num ritmo lento, tendo em vista tratar-se, por hipótese, de uma economia semiindustrializada e requerer mudanças substanciais no padrão de funcionamento da economia. Posteriormente, aumentos no nível da taxa real de câmbio possibilitarão iniciar um processo de difusão tecnológica, que ocorre num ritmo mais rápido, tendo em vista estarem assentadas as bases do padrão tecnológico. Finalmente, níveis mais elevados da taxa real de câmbio passam a ter um menor efeito sobre o processo de difusão tecnológica. Formalmente,

$$
\begin{aligned}
& \phi=\frac{\phi_{\max }}{1+\phi_{1} e^{-\phi_{\min } \theta}} \\
& \lambda=\frac{\lambda_{\max }}{1+\lambda_{1} e^{-\phi_{\min } \theta}}
\end{aligned}
$$

De acordo com a Equação (20), a participação dos tradeables high tech na pauta de exportações possui uma relação direta não linear com o nível da taxa real de câmbio, variando entre um valor mínimo $\phi_{\min }$ e um valor máximo $\phi_{\max }$. Isso porque essa categoria de bens sempre terá uma participação mínima na pauta de exportações, mas nunca a mesma se concentrará integralmente nesses bens. A Equação (21) mostra que ocorre 0 contrário com as exportações. Os parâmetros $\phi_{1}$ e $\lambda_{1}$ são positivos.

0 efeito composição também é destacado por Araújo (2012). 0 autor mostra que variações one-and-for-all no nível da taxa real de câmbio têm um importante papel na composição setorial da economia com implicações em termos da versão desagregada da lei de Thirwall, mesmo se o argumento da não importância dos movimentos quantitativos dos preços relativos se mantiver. Em outras palavras, é possível mostrar que a composição setorial da economia é fortemente afetada por movimentos permanentes da taxa de câmbio.

Em outros termos, o conjunto de elasticidade que entra na lei multissetorial de Thirwall é afetado pela competitividade dos setores, que é determinada ultimamente por movimentos na taxa de câmbio. Nesse contexto, mesmo no caso em que as elasticidades setoriais da demanda por importações e exportações são constantes, é possível concluir que 
pode haver mudanças estruturais devido a variações na taxa de câmbio que podem explicar a taxa de crescimento do produto.

Em sua estrutura analítica, seguindo Passineti $(1981,1993)$, o autor admite que existam $n-1$ setores tradeables em ambas as economias do país $A$ e do país $U$ e de que não há plena especialização. Ademais, assume-se que existe apenas um bem comercializável entre essas economias. 0 preço de cada bem em cada economia é dado por;

$$
\begin{aligned}
& p_{i}^{U}=l_{i}^{U} w^{U}, i=1, \ldots, n-1 \\
& p_{i}^{A}=l_{i}^{A} w^{A}, i=1, \ldots, n-1
\end{aligned}
$$

onde os $n-1$ coeficientes de produção de cada país são denotados por $l_{i}^{A}$ e $l_{i}^{U}$.

A taxa real de câmbio é definida como;

$$
\theta_{U / A}=q_{U / A}\left(p_{U} / p_{A}\right)
$$

em que $q_{U / A}$ é a taxa nominal de câmbio e o índices de preços dos países $A$ e $U$ são dados, respectivamente, por:

$$
\begin{aligned}
& p_{A}=\sum_{i=1}^{n-1} \rho_{i}^{A} p_{i}^{A}, \\
& p_{U}=\sum_{i=1}^{n-1} \rho_{i}^{U} p_{i}^{U},
\end{aligned}
$$

onde $\rho_{i}^{U}=\left(c_{i}^{U h}+\xi c_{i}^{U e}\right) l_{i}^{U}$ é a participação do i-th setor na renda nacional do país $U$ e $\rho_{i}^{A}=\left(c_{i}^{A h}+1 / \xi c_{i}^{A e}\right) l_{i}^{A}$ é a participação do i-th setor na renda nacional do país $A . c_{i}^{A e}$ e $c_{i}^{U e}$ são os coeficientes da demanda externa do bem i do país $A$ e $U$, respectivamente. $c_{i}^{A h} \mathrm{e}$ $c_{i}^{U h}$ são os coeficientes da demanda doméstica do bem i do país $A$ e $U$.

Com base nessa estrutura, o autor mostra numericamente que a sobrevalorização do câmbio pode prejudicar a habilidade de alguns setores de exportar tendo impacto não somente sobre a estrutura da economia, mas também sobre a taxa de crescimento. Admitindo a existência de apenas quatro setores na economia, é possível mostrar que, quando $q_{U / A}=1$, o país $U$ tem vantagens competitivas nos setores 1 e 2 , enquanto o país $A$ tem vantagens nos setores 3 e 4. Não obstante, ao considerar uma apreciação que leva a uma nova relação entre as moedas $\left(q_{U / A}=1.2\right)$, é possível mostrar que o país $U$ perde a vantagem comparativa no setor 2 .

Tradicionalmente, espera-se que, no longo prazo, a taxa nominal de câmbio retorne à sua posição inicial. Mas, durante este período de transição, pode haver mudanças estruturais na economia que desempenham um importante papel na determinação da taxa de crescimento de longo prazo. Considerando que a renda per capita na versão aberta do modelo de Pasinetti pode ser escrita como

$$
y_{U}=\sum_{i=1}^{n-1} l_{i}^{U}\left(c_{i}^{U h}+\xi c_{i}^{U e}\right)
$$

o autor mostra, no contexto do exemplo numérico, que a renda per capita antes e depois da apreciação cambial é dada por (28) e (29), respectivamente.

$$
y_{U}=l_{1}^{U}\left(c_{1}^{U h}+\xi c_{1}^{U e}\right)+l_{2}^{U}\left(c_{2}^{U h}+\xi c_{2}^{U e}\right)+l_{2}^{U}\left(c_{2}^{U h}+\xi c_{2}^{U e}\right)+l_{2}^{U}\left(c_{2}^{U h}+\xi c_{2}^{U e}\right)
$$




$$
y_{U}=l_{1}^{U}\left(c_{1}^{U h}+\xi c_{1}^{U e}\right)+l_{2}^{U}\left(c_{2}^{U h}+\xi c_{2}^{U e}\right)+l_{2}^{U}\left(c_{2}^{U h}+\xi c_{2}^{U e}\right)
$$

Considerando que a magnitude dos coeficientes de demanda são é a mesma para ambas as equações, observa-se que a renda per capita depois da desvalorização é menor.

Por fim, adotando a versão desagregada da lei de Thirwall, o autor mostra que mesmo o movimento once-and-for-all na taxa de câmbio vai ter impacto sobre a taxa de crescimento compatível com a condição de equilíbrio intertemporal do BOP. Na versão forte, a hipótese da lei de Thirwall multisetorial (Equação 6), pode ser escrita como

$$
\sigma_{y}^{U}=\frac{\sum_{i=1}^{n-1} \xi \varepsilon_{i} c_{i}^{U e} l_{i}^{U}}{\sum_{i=1}^{n-1} \pi_{i} c_{i}^{A e} l_{i}^{U}} \sigma_{y}^{A} \quad \text { com } \quad \sigma_{y}^{A}=y_{A} / y_{A}
$$

De acordo com o primeiro cenário (antes da apreciação cambial), o país $U$ exporta os bens 1 e 2 enquanto importa os bens 3 e 4. Quando a apreciação ocorre, o país $U$ inicialmente perde a vantagem comparativa em termos do bem 2,0 que significa que ele não exporta mais esse bem. Mas, quando a taxa de câmbio retorna ao seu valor inicial, o país $U$ recupera sua vantagem comparativa em termos do bem 2, mas agora a participação desse bem no total exportado vai ser diferente do valor inicial. Nesse caso, a lei de Thirwall em cada cenário é dada por

$$
\begin{gathered}
\sigma_{y b}^{U}=\frac{\varepsilon_{1} c_{1 b}^{U e} l_{1 b}+\varepsilon_{2} c_{2 b}^{U e} l_{2 b}}{\pi_{3} c_{3}^{A e} l_{3 b}+\pi_{4} c_{4}^{A e} l_{4 b}} \sigma_{y}^{A} \\
\sigma_{y b}^{U}=\frac{\varepsilon_{1} c_{1 a}^{U e} l_{1 a}+\varepsilon_{2} c_{2 a}^{U e} l_{2 a}}{\pi_{3} c_{3}^{A e} l_{3 b}+\pi_{4} c_{4}^{A e} l_{4 b}} \sigma_{y}^{A}
\end{gathered}
$$

Para comparar as duas taxas de crescimento nas expressões acima, considera-se $\varepsilon_{2}>\varepsilon_{1}$. Isso implica que o país $U$ perde competitividade com a apreciação do câmbio justamente naquele bem com maior elasticidade-renda da demanda. Quando o país $U$ recupera a vantagem comparativa em termos do bem 2 , o coeficiente $c_{2 a}^{U e}$ vai ser diferente, mas provavelmente menor do que o seu valor antes da depreciação cambial. Isso ocorre porque, primeiro, existem custos irrecuperáveis relacionados aos investimentos, e a apreciação da taxa real de câmbio pode ter induzido o investimento externo que impede que 0 coeficiente de exportação retorne ao nível anterior; segundo, a perda sofrida pelas firmas domésticas devido à apreciação pode não ser facilmente compensada pelo crescimento da demanda externa.

Em termos das expressões, como o denominador não vai sofrer mudanças significativas e como o numerador é uma media ponderada das elasticidades setoriais, é possível concluir que o numerador de (31) é, em geral, maior que o numerador de (32). Logo, mesmo variações once-and-for-all na taxa de câmbio exercem um importante papel na mudança estrutural, o que significa que a produtividade é importante, mas não decisiva em determinar a habilidade de exportar.

\section{Heterogeneidade Produtiva, Progresso Tecnológico e Endogeneidade das elasticidades.}

M issio e Jayme Jr. (2012) admitem a endogeneidade das elasticidade-renda da demanda por importações e exportações em relação ao nível da taxa real de câmbio ao pressuporem que a manutenção de um câmbio real desvalorizado gera incentivos à pesquisa e à inovação via 
efeitos sobre as condição de autofinanciamento e de acesso ao crédito, o que permite a modernização e a diversificação da capacidade produtiva. Isso implica a ampliação (diminuição) da capacidade de exportação (importar) no longo prazo.

Seguindo o trabalho de Dosi, Pavitt e Soete (1990), os autores demonstram como uma desvalorização real do câmbio, ao reduzir o salário real, afeta a heterogeneidade produtiva da economia. Não obstante, a análise desenvolvida avança em relação ao modelo original porque os autores admitem que as elasticidades-renda da demanda por importações e exportações são endógenas ao câmbio real. Ou seja, agora variações na restrição externa são decorrentes não apenas de mudanças estruturais advindas da variação salarial, mas também de um conjunto de fatores que incluem os efeitos de variações na taxa de câmbio real sobre o padrão de especialização - via efeitos sobre os salários - e também os efeitos de variações no câmbio real sobre decisões planejadas de investimento das empresas (pesquisa e inovação) e as condições de financiamento desse investimento (autofinanciamento e acesso ao crédito). Assim, demonstra-se que a mudança estrutural decorrente da manutenção que um câmbio real desvalorizado gera uma estrutura de especialização que melhora as condições de equilíbrio externo.

A análise de Dosi, Pavitt e Soete (1990) é ilustrada a seguir (Figura 1). A linha S ao longo do quadrante esquerdo superior é o lócus da relação entre os salários que garante certa especialização $(\bar{s})$. Para este nível de especialização, a linha $T B$ representa o lócus dos pontos de equilíbrio comercial. Ademais, cumpre observar que, como se consideram apenas os custos associados ao trabalho, o ângulo entre qualquer linha $f$ e 0 eixo $w$ é a medida de emprego no país $A$ e entre a linha $f^{*}$, e o eixo $w^{*}$, a medida do emprego para o país $B$.

Admite-se o par de salários, $w_{m}$ e $w_{m}^{*}$, supondo que o primeiro é o mínimo salário social aceitável no país $A$, que se iguala à produtividade média da economia com especialização $\overline{s_{0}}$ definida por $w_{m} / w_{m}^{*}$. Ademais, supõe-se que $A$ está em pleno emprego, dado pela linha $f_{T}$ (ponto $M$ ). A renda de equilíbrio para o país $A$ é então $Y_{T}$, o máximo de renda possível, enquanto para o país $B$ isso é dado pelo ponto $Y_{T}^{*}$. Observe-se que este ponto pode corresponder a um nível de renda menor que o de pleno emprego. Digamos que o ponto de pleno emprego para o país $B$ seja definido pela linha $f_{T}^{*}$. Como ilustrado na figura, isto não pode ser alcançado, dada a restrição externa de equilíbrio comercial (linha $T B$ ). Logo, no ponto $R$, o país $B$ está em desemprego. 


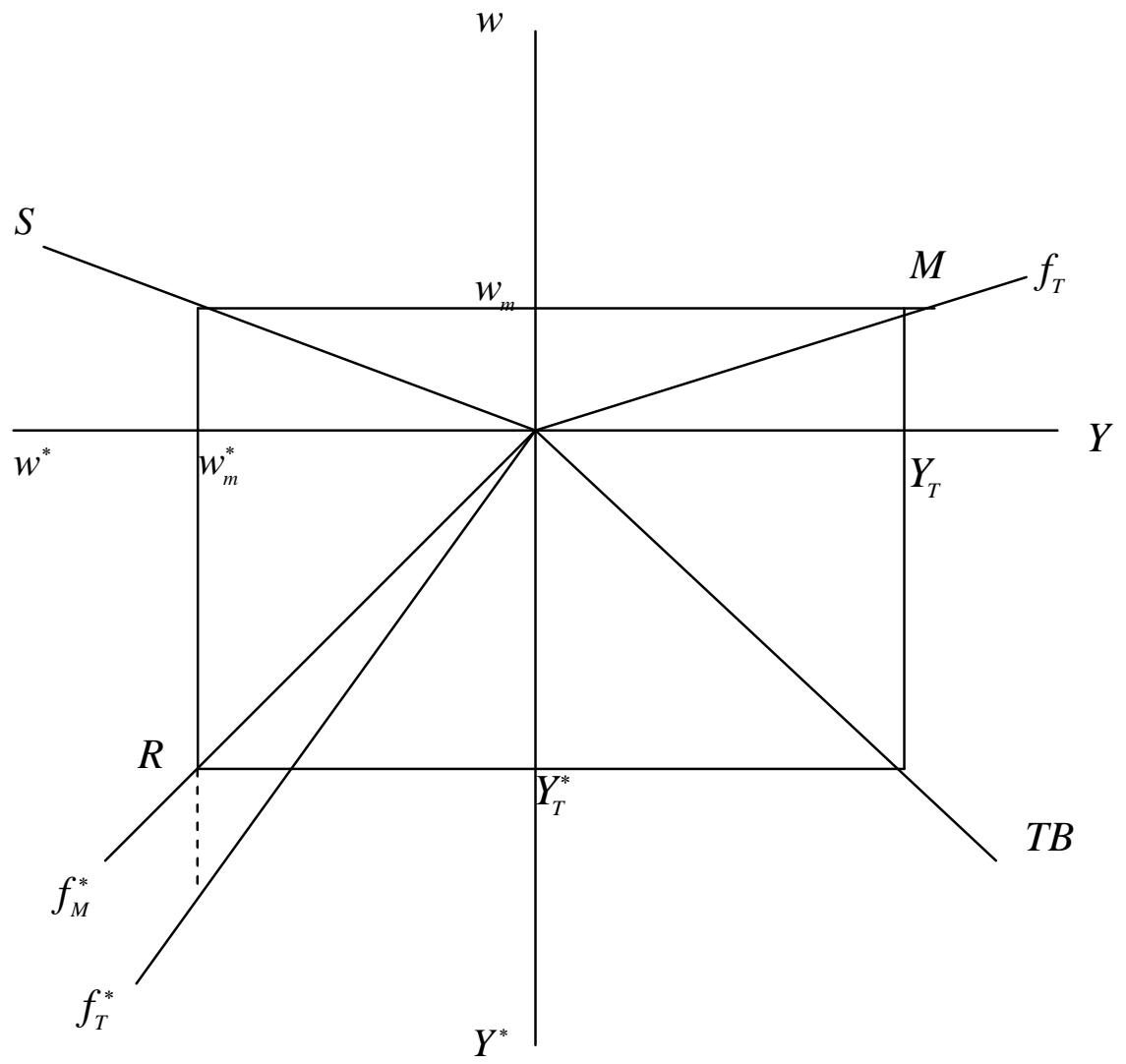

Figura 1: Especialização, Restrição Externa e Crescimento.

Agora analisam-se os efeitos de uma outra combinação de taxas de salário para os dois países (digamos $w>w_{m}$ e $w^{*}<w_{m}^{*}$ ), dadas as condições de tecnologia e demanda. Isso significa, em termos da Figura 1, que a linha $S$ vai girar no sentido horário (de $S_{1}$ para $S_{2}$ ), aumentando o número de commodities produzido por $B$. A linha $T B$ faz rotação no mesmo sentido (de $T B_{1}$ para $T B_{2}$ ), dado que a propensão a importar cresceu em $A$ e decresceu em $B$ (Figura 2).

Como pode ser observado, agora o salário por trabalhador e a produtividade média do trabalho em $A$ é maior, mas esse país deve sofrer um aperto na restrição advinda da condição de equilíbrio externo, uma vez que suas necessidades de importações aumentaram.

0 ponto considerado pelos autores é justamente o mecanismo que desloca as curvas $S$ e $T B$ que estão além daqueles apontados por Dosi, Pavitt e Soete (1990). Observe que a análise é construída originalmente admitindo-se variações na razão salarial (que podem advir de variações na taxa de câmbio), mas mantendo-se devido às condições de tecnologia. Ademais, as variações nas elasticidades admitidas na análise não são completamente explicadas. Sendo assim, o que Missio e Jayme Jr. (2012) argumentam é que variações no câmbio real, ao alterar o progresso tecnológico e, portanto, a produtividade, é capaz de deslocar a curva $T B$, ainda que a razão salarial não tenha se alterado. Na medida em que aumenta o progresso técnico e, portanto, o conteúdo tecnológico incorporado nos produtos, melhora a atratividade no que tange à demanda externa e à capacidade de atender a demanda doméstica dos bens produzidos internamente. Ou seja, alteram-se as elasticidades- 
renda e, consequentemente, a restrição externa ao crescimento. Nesse caso, tem-se o mecanismo que explica a endogeneidade das elasticidades.



Figura 2: Especialização, Restrição Externa e Crescimento sob novo $\omega$

Em síntese, argumenta-se que a elasticidade-renda da demanda por exportações é uma função direta, entre outros fatores, do número de produtos produzidos pelo país e do grau de tecnologia incorporado nesses produtos. Em relação ao número de produtos, variações no câmbio real alteram o salário real, levando à diversificação ou à especialização da produção. Isso porque, quanto ocorre um aumento dos salários reais, por exemplo, os setores que já competem com desvantagens no mercado internacional, dado o baixo conteúdo tecnológico incorporado em seus produtos, perdem mercados ou deixam de existir, forçando a economia a se especializar em setores onde existem vantagens comparativas naturais. Para países em desenvolvimento, isso significa a especialização na produção de produtos naturais primários. Acontece que a elasticidade- renda da demanda por exportações desses produtos é baixa, o que mostra que a especialização nestes setores impõe uma maior restrição ao crescimento com equilíbrio externo. Por outro lado, uma redução nos salários reais (desvalorização) leva a uma diversificação produtiva, o que, no longo prazo, representa uma maior capacidade de exportar e uma menor dependência das importações. Argumento semelhante é desenvolvido por Bresser-Pereira, Oreiro e M arconi $(2015)^{14}$.

\footnotetext{
${ }^{14}$ Em síntese, o argumento apresentado pelos autores é que a desvalorização da taxa real de câmbio afeta a heterogeneidade produtiva da economia e reduz o salário real relativo e os custos unitários do trabalho. Isso tende a mudar o nível de especialização internacional, crescendo o número de bens que são manufaturados no país e, consequentemente, a participação da indústria no produto.
} 
Em relação ao grau de sofisticação dos produtos, os autores observam que a desvalorização cambial - ao aumentar o lucro das empresas e a sua capacidade de autofinanciamento - altera a disponibilidade de fundos que as empresas dispõem para realizarem seus projetos de investimentos relacionados à pesquisa e inovação. Em outros termos, o argumento é de que a valorização do câmbio real está associada a uma redistribuição (temporária) de renda dos lucros em prol dos salários, o que implica uma redução da capacidade de autofinanciamento das empresas que se reflete na diminuição da disponibilidade de fundos próprios para aquisição de novas tecnologias e na maior restrição de acesso das firmas ao financiamento de terceiros devido às assimetrias de informação existentes nos mercados financeiros, as quais geram racionamento de crédito. Dessa forma, mesmo diante da possibilidade de aquisição de tecnologia barata no exterior, é provável que diversos setores produtivos mantenham-se incapacitados de investir na modernização da sua capacidade produtiva, haja vista a escassez de autofinanciamento e 0 racionamento de crédito. Portanto, é diante da manutenção de um câmbio competitivo que se espera que as empresas empreendam atividades inovativas que resultem em uma maior heterogeneidade produtiva (maior número de tipos diferentes de bens produzidos, por exemplo) e, também, em uma homogeneização estrutural, visto que agora o progresso técnico é incorporado também por setores que não estão vinculados ao mercado externo. Como nos setores mais atrasados os retornos da atividade inovativas são maiores, espera-se que as descontinuidades sejam rapidamente superadas.

Assim, o nível da taxa real de câmbio afeta a estrutura da oferta da economia, no sentido de que a referida taxa influencia a intensidade tecnológica ou, mais especificamente, 0 quantum de tecnologia que é produzido e incorporado na produção doméstica. Isso implica 0 aumento da produção tradables high tech e a geração de um saldo favorável advindo da comercialização desses bens na balança comercial ${ }^{15}$.

Formalmente, admite-se que as referidas elasticidades são endógenas ao nível real da taxa de câmbio (M issio, 2012), i.e.;

$$
\begin{aligned}
& \varepsilon_{0}=f\left(\bar{s}_{\left(\theta_{0}\right)}, a_{\left(\theta_{0}\right)}\right) \quad \text { com } \frac{\partial \varepsilon}{\partial \bar{s}} \cdot \frac{\partial \bar{s}}{\partial \theta}>0 ; \frac{\partial \varepsilon}{\partial a} \cdot \frac{\partial a}{\partial \theta}>0 \\
& \pi_{0}=f\left(\bar{s}_{\left(\theta_{0}\right)}, a_{\left(\theta_{0}\right)}\right) \quad \operatorname{com} \frac{\partial \pi}{\partial \bar{s}} \cdot \frac{\partial \bar{s}}{\partial \theta}<0 ; \frac{\partial \pi}{\partial a} \cdot \frac{\partial a}{\partial \theta}<0
\end{aligned}
$$

em que $\bar{s}_{\left(\theta_{0}\right)}$ é o número de bens produzidos pelo país, $a_{\left(\theta_{0}\right)}$ é o progresso tecnológico e $\theta$ é 0 nível da taxa real de câmbio. Observe que se $\theta_{1}$, por exemplo, for maior do que $\theta_{0}$, então vale a seguinte relação para as elasticidades: $\varepsilon_{1}>\varepsilon_{0}$ e $\pi_{0}>\pi_{1}$.

Sendo assim, é possível reescrever a Equação (5) como:

$$
y=[\varepsilon(\theta) / \pi(\theta)] z
$$

Ou seja, a taxa de crescimento compatível com o equilíbrio do balanço de pagamentos é igual à multiplicação entre a razão da elasticidade renda da demanda por exportações e a

\footnotetext{
${ }^{15}$ Esse é um ponto de complementariedade entre os trabalhos de Missio e Jayme Jr (2012) e Ferrari, Freitas e Barbosa-Filho (2013).
} 
elasticidade renda da demanda por importações (ambas dependentes do câmbio real) pela taxa de crescimento da renda do resto do mundo.

Diferenciando a Equação (35) com relação à taxa de câmbio real, tem-se que:

$$
\frac{\partial y}{\partial \theta}=\left\{[\pi(\theta) \cdot \overbrace{\frac{\partial \varepsilon(\theta)}{\partial \theta}}^{+}-\varepsilon(\theta) \cdot \overbrace{\frac{\partial \pi(\theta)}{\partial \theta}}^{-}] . z\right\} /[\pi(\theta)]^{2}>0
$$

\section{Endogeneidade das Elasticidades nos Modelos norte-sul}

Botta (2009) desenvolve uma análise formal em que interagem duas regiões, uma desenvolvida (Norte) e a outra em desenvolvimento (Sul), a partir da estrutura de um modelo de crescimento com restrição externa. Em cada uma dessas regiões, a ênfase recai sobre a manufatura, e sua participação no produto doméstico (a preços constantes) é a variável econômica usada para descrever o processo de industrialização.

A elasticidade-renda das exportações (importações), $\varepsilon_{n t}\left(\varepsilon_{s t}\right)$, no Sul, é uma função positiva (negativa) da participação das manufaturas no produto doméstico. Ou seja, as elasticidades-renda da demanda por importações-exportações são endógenas, sendo sua evolução dependente dos efeitos da industrialização do Sul sobre o padrão das elasticidades renda das importação/exportações.

$$
\varepsilon_{s t}=\frac{2 \varepsilon^{*}}{1+e^{\left[\ln \left(G_{s t} / G_{n t}\right)\right] / \phi}}
$$

com

$$
\frac{\partial \varepsilon_{s t}}{\partial\left(G_{s t} / G_{n t}\right)}=-\frac{2 \varepsilon^{*}}{\phi} \cdot \frac{\left[1 /\left(G_{s t} / G_{n t}\right)\right] \cdot e^{\left[\ln \left(G_{s t} / G_{n t}\right)\right] / \phi}}{\left[1+e^{\left[\ln \left(G_{s t} / G_{n t}\right)\right] / \phi}\right]^{2}}<0
$$

e

$$
\varepsilon_{n t}=\frac{2 \varepsilon^{*}}{1+e^{-\left[\ln \left(G_{s t} / G_{n t}\right)\right] / \phi}}
$$

com

$$
\frac{\partial \varepsilon_{n t}}{\partial\left(G_{s t} / G_{n t}\right)}=\frac{2 \varepsilon^{*}}{\phi} \cdot \frac{\left[1 /\left(G_{s t} / G_{n t}\right)\right] \cdot e^{-\left[\ln \left(G_{s t} / G_{n t}\right)\right] / \phi}}{\left[1+e-^{\left[\ln \left(G_{s t} / G_{n t}\right)\right] / \phi}\right]^{2}}>0
$$

em que, nas Equações (37) e (38), $G_{s t}\left(G_{n t}\right)$ é a participação real das manufaturas no produto no Sul (Norte); $\varepsilon^{*}$ é o nível uniforme das elasticidades renda das importações (exportações) no caso de identidade entre as estruturas produtivas; e $\phi$ é o parâmetro tecnológico. Admitese que $G_{n t}$ seja o nível mais alto de industrialização alcançável, tal que $0 \leq G_{s t} / G_{n t} \leq 1^{16}$.

${ }^{16}$ Admite-se que $G_{s t}=\left[G_{s 0}\left(1+y_{s 0}\right)\right] A$ com $A=\left\{\prod_{i=1}^{t-1}\left[1+\sigma^{i} y_{s i}\right]\right\}$, em que $G_{s 0}$ é o nível exógeno de industrialização do Sul no início do processo, enquanto $y_{s 0}$ é o conjunto de condições iniciais. 
Como observado, a industrialização determina a diversificação do padrão produtivo doméstico e muda a composição do fluxo dos produtos de exportação e importação. Ademais, a elasticidade-renda da demanda por exportação (importação) é positivamente (negativamente) relacionada com o grau de desenvolvimento da industrialização doméstica.

Seguindo a literatura evolucionária, fatores tecnológicos aumentam a competitividade não preço dos produtos domésticos em relação aos produtos estrangeiros. No modelo, isso pode ser observado, diferenciando $\varepsilon_{s t}$ e $\varepsilon_{n t}$ com respeito a $\phi$;

$$
\begin{gathered}
\frac{\partial \varepsilon_{s t}}{\partial \phi}=-\frac{2 \varepsilon^{*}}{\phi^{2}} \cdot \frac{\left[\ln \left(G_{s t} / G_{n t}\right)\right] \cdot e^{\left[\ln \left(G_{s t} / G_{n t}\right)\right] / \phi}}{\left[1+e^{\left[\ln \left(G_{s t} / G_{n t}\right)\right] / \phi}\right]^{2}}<0 \\
\frac{\partial \varepsilon_{n t}}{\partial \phi}=\frac{2 \varepsilon^{*}}{\phi^{2}} \cdot \frac{\left[-\ln \left(G_{s t} / G_{n t}\right)\right] \cdot e^{-\left[\ln \left(G_{s t} / G_{n t}\right)\right] / \phi}}{\left[1+e-^{\left[\ln \left(G_{s t} / G_{n t}\right)\right] / \phi}\right]^{2}}>0
\end{gathered}
$$

Em resumo, tudo ou mais constante, maiores valores de $\phi$ aumentam a competitividade no preço dos produtos do Sul, o que implica uma maior (menor) elasticidade renda das exportações (importações) ${ }^{17}$.

0 modelo desenvolvido por Missio e Jayme Jr (2013), baseado em Cimoli e Porcile (2011), mostra o efeito de uma desvalorização no nível da taxa real de câmbio sobre 0 crescimento das economias em desenvolvimento, considerando-se o comércio internacional. Admitindo que os gastos planejados em inovação das empresas presentes nessas economias são mais fortemente dependentes do lucro acumulados e, por conseguinte, do nível da taxa real de câmbio, os autores demonstram que, mesmo que os países desenvolvidos adotem políticas semelhantes (retaliatória) de desvalorização cambial, ainda assim haverá um efeito positivo sobre o crescimento dessas economias ${ }^{18}$. Para tanto, desenvolve-se um modelo Norte-Sul, onde o Sul são os países que estão crescendo abaixo do seu potencial máximo devido à restrição externa (países em desenvolvimento, Grupo 1), enquanto os países do Norte não "desejam" aumentar suas taxas de crescimento (países desenvolvidos, Grupo 2). 0 que diferencia o grau de desenvolvimento dos países é a dependência da acumulação do progresso tecnológico às variações no nível da taxa real de câmbio. Para o segundo grupo de países, assume-se que essa dependência é nula.

A justificativa para esta diferenciação está no entendimento de que, nos países desenvolvidos, a tecnologia é mais diversificada, o que, somado às características de dependência de trajetória e do seu caráter cumulativo, faz com que seja menos dependente dos incentivos advindos da política cambial. Mais especificamente, entende-se que uma redistribuição da renda em prol dos lucros afeta o progresso tecnológico para ambos o grupo de países, mas, nos países desenvolvidos, esses efeitos são reduzidos, dado que grande parte do progresso tecnológico é resultado da própria atividade produtiva. Segundo Rosemberg (1982), o acúmulo de conhecimento tecnológico (muitas vezes resultante de achados puramente empíricos ou de solução de problemas técnicos na produção) oferece avenidas para o desenvolvimento da ciência. 0 autor relata o surgimento de problemas complexos em

\footnotetext{
${ }^{17}$ Observa-se que os trabalhos de Botta (2009) e Missio e Jayme Jr (2011) são complementares. 0 primeiro mostra que as elasticidades-renda são endógenas a tecnologia e, o segundo, que a tecnologia depende do nível da taxa real de câmbio. Logo, é fácil perceber a generalização de que as referidas elasticidades são endógenas ao câmbio real.

${ }^{18}$ Evidentemente, desconsidera-se a possibilidade de uma "guerra fiscal" que reduza drasticamente 0 nível de comércio.
} 
empresas cuja solução resulta em descobertas científicas importantes. Ou seja, a dinâmica de aplicação da ciência à produção determina novos canais de evolução da própria ciência, específicos desta dinâmica. Como salienta Dosi (1988), um significativo montante da inovação e de melhoramentos é originado através de melhoramentos, "learning by doing" e "learning by using". Nesse contexto, o maior número de empresas (concorrentes potenciais) e a maior integração desses mercados à economia mundial, juntamente com a presença de um sistema nacional de inovações consolidado, deixa o progresso tecnológico nos países desenvolvidos menos dependente do nível da taxa real de câmbio (M issio e Jayme Jr., 2013).

Formalmente, a estrutura inicial do modelo de Cimoli e Porcile (2011) é apresentada como segue: o nível de renda real dos dois grupos (medidos em termos monetários do Grupo 1) pode ser expresso da seguinte forma:

$$
\begin{aligned}
& Y_{1}=C_{1}+I_{1}+G_{1}+X_{1}-M_{1} \cdot\left(E \cdot P_{2} / P_{1}\right) \\
& Y_{2}=C_{2}+I_{2}+G_{2}+X_{2}-M_{2} \cdot\left(P_{1} / E \cdot P_{2}\right) \\
& y_{i}=\left(\pi_{j} / \pi_{i}\right) y_{j}
\end{aligned}
$$

em que $Y_{i}=$ renda, $C_{i}$ = consumo, $I_{i}=$ investimento, $G_{i}=$ gasto do governo, $y_{i}=$ a taxa de crescimento compatível com equilíbrio em conta corrente do país $i, y_{j}=$ taxa de crescimento do país $j, i, j=1,2$ e $i \neq j$. A Equação (43) é a restrição externa para uma economia sem fluxo de capitais (considerando $e+p_{2}=p_{1}$ ) (Thirlwall, 1979).

Por simplicidade, admite-se que consumo, investimento e gasto do governo são funções apenas do gasto autônomo. Nesse sentido, o nível de gasto autônomo agregado $\left(B_{i}\right)$ pode ser identificado como;

$$
B_{i}=C_{i}+I_{i}+G_{i}
$$

Logo, substituindo (44) nas Equações (41) e (42), é possível reescrever a renda nacional dos dois grupos;

$$
\begin{aligned}
& Y_{1}=B_{1}+X_{1}-M_{1} \cdot\left(E \cdot P_{2} / P_{1}\right) \\
& Y_{2}=B_{2}+X_{2}-M_{2} \cdot\left(P_{1} / E . P_{2}\right)
\end{aligned}
$$

Reescrevendo as Equações (2) e (3) em termos de taxas de crescimento e considerando o modelo com duas regiões, $\eta_{1}=\psi_{2}, \eta_{2}=\psi_{1}, \varepsilon_{1}=\pi_{2}$ e $\varepsilon_{2}=\pi_{1}$, tem-se:

$$
\begin{aligned}
& x_{1}=m_{2}=\pi_{2} \cdot y_{2}-\eta_{1} \cdot\left(e+p_{2}-p_{1}\right) \\
& m_{1}=x_{2}=\pi_{1} \cdot y_{1}+\psi_{1} \cdot\left(e+p_{2}-p_{1}\right)
\end{aligned}
$$

Reescrevendo (45) e (46) em termos de taxa de crescimento e substituindo no resultado as Equações (47) e (48), é possível determinar a taxa de crescimento para ambos os grupos como;

$$
\begin{aligned}
& y_{1}=\alpha_{1} \cdot b_{1}+\beta_{1} \cdot \pi_{2} \cdot y_{2}-\beta_{1} \cdot(1+\eta+\psi) \cdot\left(e+p_{2}-p_{1}\right) \\
& y_{2}=\alpha_{2} \cdot b_{2}+\beta_{2} \cdot \pi_{1} \cdot y_{1}+\beta_{2} \cdot(1+\eta+\psi) .\left(e+p_{2}-p_{1}\right)
\end{aligned}
$$

onde $b_{1}$ e $b_{2}$ são as taxas de crescimento dos gastos autônomos e $\alpha_{i}=\beta_{i}=1 /\left(1+\pi_{i}\right)$ são os multiplicadores. 
Resolvendo o sistema formado por (49) e (50), é possível demonstrar que as taxas de crescimento podem ser expressas em termos de $b_{1}$ e $b_{2}$ e das taxas de mudança dos termos de troca. Ou seja;

$$
\begin{aligned}
& y_{1}=\frac{\left[\left(\alpha_{1} \cdot b_{1}+\beta_{1} \cdot \pi_{2} \cdot \alpha_{2} \cdot b_{2}\right)-\beta_{1} \cdot\left(1-\beta_{2} \cdot \pi_{2}\right) \cdot(1+\eta+\psi) \cdot\left(e+p_{2}-p_{1}\right)\right]}{\left(1-\beta_{1} \cdot \beta_{2} \cdot \pi_{1} \cdot \pi_{2}\right)} \\
& y_{2}=\frac{\left[\left(\alpha_{2} \cdot b_{2}+\beta_{2} \cdot \pi_{1} \cdot \alpha_{1} \cdot b_{1}\right)+\beta_{2} \cdot\left(1-\beta_{1} \cdot \pi_{1}\right) \cdot(1+\eta+\psi) \cdot\left(e+p_{2}-p_{1}\right)\right]}{\left(1-\beta_{1} \cdot \beta_{2} \cdot \pi_{1} \cdot \pi_{2}\right)}
\end{aligned}
$$

em que $1-\beta_{1} \cdot \beta_{2} \cdot \pi_{1} \cdot \pi_{2}>0$.

A seguir, com base em (51) e (52), analisam-se os efeitos de uma política de desvalorização da taxa real de câmbio incluindo no modelo a hipótese de endogeneidade das elasticidades-renda do comércio em relação ao nível da taxa real de câmbio. Para simplificar a análise, Missio e Jayme Jr. (2013) admitem que o progresso tecnológico não altera a elasticidade-renda da demanda por importações.

Ademais, para determinar a influência de variações no nível da taxa real de câmbio do Grupo (1), considera-se que as variações na taxa real de câmbio sejam nulas $\left(\hat{\theta}=e+p_{2}-p_{1}=0\right)$. Ou seja, admite-se que o Grupo (1) adotou uma política que elevou 0 nível da taxa real de câmbio permanentemente, sendo a variação nessa taxa nula a partir do momento em que ela alcançou este novo patamar $\left(\theta_{1}\right)^{19}$. Os efeitos dessa alteração sobre as taxas de crescimento dos dois grupos podem ser determinados diferenciando parcialmente as Equações (51) e (52) com respeito à $\theta_{1}$. Nesse caso, leva-se em consideração o aumento na elasticidade-renda da demanda de exportações do Grupo (1) e, consequentemente, a elevação da elasticidade-renda da demanda por importações do Grupo (2). Consideram-se também os efeitos sobre $\alpha_{2}$ e $\beta_{2}$, ou seja, o fato de que os multiplicadores também são endógenos, com $\left(\partial \beta_{2} / \partial \pi_{2}^{*}\right) .\left(\partial \pi_{2}^{*} . \partial \theta_{1}\right)<0$ e $\left(\partial \alpha_{2} . \partial \pi_{2}^{*}\right) .\left(\partial \pi_{2}^{*} . \partial \theta_{1}\right)<0$.

Sendo assim, reescrevendo as Equações (51) e (52) (explicitando a endogeneidade dos multiplicadores e das elasticidades);

$$
\begin{aligned}
& y_{1}=\left[\alpha_{1} \cdot b_{1}+\beta_{1} \cdot \pi_{2}^{*}\left(\theta_{1}\right) \cdot \alpha_{2}\left(\theta_{1}\right) \cdot b_{2}\right] /\left[1-\beta_{1} \cdot \beta_{2}\left(\theta_{1}\right) \cdot \pi_{1} \cdot \pi_{2}^{*}\left(\theta_{1}\right)\right] \\
& y_{2}=\left[\alpha_{2}\left(\theta_{1}\right) \cdot b_{2}+\beta_{2}\left(\theta_{1}\right) \cdot \pi_{1} \cdot \alpha_{1} \cdot b_{1}\right] /\left[1-\beta_{1} \cdot \beta_{2}\left(\theta_{1}\right) \cdot \pi_{1} \cdot \pi_{2}^{*}\left(\theta_{1}\right)\right]
\end{aligned}
$$

e derivando com relação a $\theta_{1}$ (nível da taxa real de câmbio do grupo 1), os autores mostram que $\partial y_{1} / \partial \theta_{1}>0$ e $\partial y_{2} / \partial \theta_{1}=(?)$, ou seja, que a política de desvalorização do câmbio real pelo Grupo (1) tem efeitos positivos sobre a sua taxa de crescimento de longo prazo. Uma política de retaliação por parte do Grupo (2) é inócua, uma vez que as mudanças decorrentes de variações no nível da taxa real de câmbio do primeiro grupo são estruturais e, portanto, permanentes.

0 resultado anterior mostra, ainda, que os efeitos sobre a taxa de crescimento do Grupo (2) é indeterminado. No entanto, espera-se que ele seja negativo. Uma forma de observar isso é demonstrar os efeitos dessa variação sobre a restrição externa dos dois grupos de países. Reescrevendo (43) em termos do Grupo (1) e do Grupo (2) e diferenciando,

\footnotetext{
${ }^{19}$ Para propostas de como implementar esta política, ver Frenkel e Taylor (2006) e Ferrari, Freitas e Barbosa-Filho (2013).
} 


$$
\begin{aligned}
& \partial y_{1} / \partial \theta_{1}=\left[\left(\partial \pi_{2}^{*} / \partial \theta_{1}\right) \cdot \pi_{1} /\left(\pi_{1}\right)^{2}\right] \cdot y_{2}>0 \\
& \partial y_{2} / \partial \theta_{1}=\left[\left(-\partial \pi_{2}^{*} / \partial \theta_{1}\right) \cdot \pi_{1} /\left(\pi_{2}\right)^{2}\right] \cdot y_{1}<0
\end{aligned}
$$

0 resultado (55) demonstra que, para uma dada renda do Grupo (2), um aumento no nível da taxa real de câmbio do Grupo (1) relaxa a sua restrição externa, o que implica a possibilidade de se alcançar uma maior taxa de crescimento de longo prazo compatível com o equilíbrio no BP. Em outras palavras, quanto maior o grau de competitividade não preço do Grupo (1) comparado ao Grupo (2) (isto é, maior a relação $\pi_{2} / \pi_{1}$ ), maior vai ser a taxa de crescimento desse grupo compatível com o equilíbrio no BP para uma dada taxa de crescimento do Grupo (2).

\section{Modelo Multissetorial com Endogeneidade das Elasticidades}

A partir de uma abordagem formal, Missio, Araújo e Jayme Jr. (2013) estendem o modelo desenvolvido por Araújo e Lima (2007), derivando uma taxa de crescimento com equilíbrio no Balanço de pagamentos análogo à Lei de Thirlwall a partir de um modelo macrodinâmico multissectorial pasinettiano que admite a hipótese de endogeneidade das elasticidades em relação ao nível da taxa real de câmbio. Nessa estrutura formal, incorporam-se as hipóteses de endogeneidade das elasticidades-renda do comércio exterior e do progresso tecnológico. Além disso, 0 modelo é construído relacionando crescimento, taxa real de câmbio e heterogeneidade setorial.

Considerando apenas a hipótese de endogeneidade das elasticidades, a lei multissetorial de Thirlwall (1979) passa a ser dada por;

$$
\sigma_{y}^{U}=\frac{\sum_{1=1}^{n-1} \xi \beta_{i}(\theta) a_{i \hat{n}} \cdot a_{n i}}{\sum_{1=1}^{n-1} \phi_{i}(\theta) a_{\hat{i} n} \cdot a_{n i}} \sigma_{y}^{A}
$$

A Equação (57) é semelhante à Equação (6). Os resultados associados a esta última equação continuam válidos na nova versão. Não obstante, agora a referida lei depende do nível da taxa real de câmbio, uma vez que as elasticidades são endógenas. Isso implica que 0 país $U$ pode alcançar um maior crescimento da renda per capita, para uma dada taxa de crescimento da renda do resto do mundo, se mantiver um nível competitivo para a taxa real de câmbio. Isso porque a hipótese de endogeneidade das elasticidades admite que essa variável é um importante instrumento capaz de induzir a mudança estrutural e, portanto, determinar mudanças no coeficiente de proporcionalidade (primeiro termo do lado direito da equação) bem como aumentar a taxa de crescimento das suas exportações. Logo, uma das principais implicações do resultado alcançado é mostrar que a condução da política econômica de curto prazo pode afetar o crescimento de longo prazo (path dependence).

\section{Considerações Finais}

Os trabalhos analisados mostram que desenvolvimentos recentes ampliam a abordagem dos modelos BPCG, incorporando novos mecanismos de transmissão e novos efeitos de uma série de variáveis, a destacar o nível da taxa real de câmbio, que são capazes de relaxar a restrição advinda da condição de equilíbrio no balanço de pagamentos. Mais que isso, os novos desdobramentos mostram que o gerenciamento da política econômica de curto prazo pode influenciar a capacidade de a economia crescer no longo prazo. 
A hipótese de endogeneidade das elasticidades é recente e mais recente são os trabalhos que a admitem em relação à taxa real de câmbio. Em geral, ao incorporar essa hipótese, os trabalhos mostram que a política cambial pode influenciar o crescimento não apenas por possibilitar o aumento da competitividade de curto prazo mas também por atuar no sentido de prover os incentivos necessários ao investimento e ao maior desenvolvimento tecnológico, o que implica a capacidade de influenciar as condições de oferta de longo prazo, sobretudo no que tange à pauta de exportações. Em outras palavras, além das mudanças de curto prazo nas elasticidades-preço da demanda por exportações e importações, variações no nível da taxa real de câmbio também têm efeito de longo prazo sobre o crescimento através de seus impactos sobre as elasticidades- renda do comércio.

Sendo assim, os novos desenvolvimentos dessa literatura caminham no sentido de propor análises que integram aspectos de curto e de longo prazo na interpretação que evidencia, em especial para países em desenvolvimento, os efeitos positivos da manutenção da taxa de câmbio em um nível estável e competitivo, destacando os processos de retroalimentação entre a micro e a macroeconomia. Por exemplo, ao reconhecer os efeitos indiretos que a taxa real de câmbio possui sobre a estrutura produtiva, é possível demonstrar a importância dessa política para o crescimento de longo prazo e justificar a interferência estatal (Oreiro, Missio e Jayme Jr., 2015). Ademais, ressalta-se a argumentação de que, em contraposição a algumas abordagens econômicas, enfatiza-se a política cambial como importante instrumento capaz de orientar o processo de formação do capital, em especial, em direção a setores intensivos em tecnologia. Ou seja, os novos desenvolvimentos dessa literatura não consideram apenas os efeitos "competitividade-preço", mas, principalmente, os efeitos de variações na taxa real de câmbio sobre a "competitividade não preço".

Além disso, a prioridade concedida aos efeitos do câmbio real sobre a inovação tecnológica permite mudanças das vantagens comparativas de caráter estático, baseada na dotação de fatores, para as vantagens competitivas dinâmicas, que culminam na melhoria dos níveis de produtividade, qualidade e diversificação dos bens e serviços. Nesse sentido, admitese que a taxa real de câmbio, além das ações que assegurem o bom comportamento dos "grandes preços" da economia, também seja de fundamental importância na articulação da "arquitetura meso e microeconômica" destinadas a construir vantagens comparativas dinâmicas baseadas na aprendizagem e no conhecimento. Em outros termos, enfatiza-se que variações no nível da taxa real de câmbio geram mudanças estruturais consideráveis, como, por exemplo, no padrão de especialização produtiva e na proporção entre a produção nacional e importações no total de bens comercializados em cada mercado e/ou nas participações relativas dos distintos tipos de firmas no interior de cada mercado e nas formas de organização da produção em cada firma, entre outras.

O desafio dessa abordagem é avançar nesses desdobramentos teóricos, mas especialmente ampliar a investigação empírica ${ }^{20}$. Do ponto de vista teórico, alguns trabalhos recentes têm demonstrado a existência de importantes conexões com outras abordagens econômicas, especialmente a evolucionária, institucionalista e neokaleckiana, que permitem avançar na construção de um núcleo teórico comum capaz de ampliar as explicações acerca dos determinantes fundamentais das elasticidades-renda do comércio internacional ${ }^{21}$. Em

\footnotetext{
${ }^{20}$ Para evidências empíricas acerca da endogeneidade das elasticidades, ver M issio (2012); Jayme Jr.; Campos e Brito (2014) e M arconi, Araújo e Oreiro (2015).

${ }^{21}$ A integração entre diferentes abordagens tem sido o foco de uma série de trabalhos, não necessariamente apenas dentro da abordagem dos modelos BPCG. Por exemplo, Llerena and Lorentz (2004a, 2004b) contribuem na direção de articular a visão schumpeteriana de tecnologia com o efeito
} 
outras palavras, a hipótese de endogeneidade deve levar em consideração também a influência de outras variáveis, como, por exemplo, o Sistema Nacional de Inovações de um país e o conjunto de suas Instituições e/ou a distribuição funcional da renda (Resende e Torres, 2008, Jayme Jr. e Resende, 2009; Catela e Porcile, 2012; Gabriel e Missio, 2014; Gabriel, Oreiro e Jayme Jr, 2015; M issio, Jayme Jr e Conceição, 2015; Ribeiro, M cCombie e Lima, 2015).

\section{Referências}

Amado, A.; Dávila-Fernández, M. (2015), "Entre a lei de Thirlwall e a hipótese Prebisch-Singer: uma avaliação da dinâmica dos termos de troca em um modelo de crescimento com restrição no Balanço de Pagamentos", Economia e Sociedade, Campinas, v. 24, n. 1 (53), 87119.

Alonso, J. A.; Garcimartin, C. (1998-1999), "A new approach to balance-of-payments constraint: some empirical evidence", Journal of Post Keynesian Economics, 21 (2), 259-282.

Araujo, R. A.(2012) "Efeitos de variações cambiais em uma abordagem de dinâmica de mudança estrutural à teoria do crescimento restrito pelo balanço de pagamentos",Economia e Sociedade,campinas, 21, 585-606.

Araujo, R. A.; Lima, G. T. (2007) "A structural economic dynamics approach to balanceofpayments-constrained growth", Cambridge Journal of Economics, 31 (5), 755-774.

Atesoglu, H. (1993) "Balance-of-payments-constrained growth model: evidence the United States. Journal of Post-Keynesian Economics,15(4), 507-514.

Bairam, E. (1993) "Static versus dynamic specifications and the Harrod foreign trade multiplier",Applied Economics, 25 (6), 739-742.

Barbosa-Filho, N. (2006) "Exchange rates, growth and inflation", Paper presented at the Annual Conference on Development and Change, Campos do Jordão, Brazil, November.

Baldwin, R. and Krugman, P. (1989) "Persistent Trade Effects of Large Exchange Rate Shocks", The Quaterly Journal of Economics, 104(4), 635-654.

Bértola, L.; Higachi, H.; Porcile, G. (2002) "Balance-of-payments-constrained growth in Brazil: a test of Thirlwall's Law, 1890-1973", Journal of Post Keynesian Economics, 25 (11), 123-140.

Boianovsky, M.; Solís, R. (2014) "The Origins and Development of the Latin American Structuralist Approach to the Balance of Payments, 1944-1964", Review of Political Economy, 26, 23-59.

Botta, A. (2009) "A structuralist north-south model on structural change, economic growth and catching-up", Structural change and Economic Dynamics, 20, 61-73.

Bresser-Pereira, L. C., Oreiro, J. L. and Marconi, N. (2015) “Developmental Macroeconomics: New Developmentalism as a Growth Strategy",London: Routledge.

Carvalho, V. R. (2005) "A restrição externa e a perda de dinamismo da economia brasileira: investigando as relações entre estrutura produtiva e crescimento econômico", Dissertação (M estrado)-IPE-FEA-USP, SãoPaulo.

Carvalho, V. R.; Lima, G. T. (2008) "Macrodinâmica do produto e da renda sob restrição externa: a experiência brasileira no período 1930-2004", Economia Aplicada, 12 (1), 55-77.

demanda via Lei de Verdoorn, enquanto León-Ledesma (2000) também avança ao modelar o processo de causação circular cumulativa dentro da tradição pós keynesiana. 
Carvalho, V. R.; Lima, G. T. (2009) "Estrutura produtiva, restrição externa e crescimento econômico: a experiência brasileira", Economia e Sociedade, Campinas, 18 (1), 31-60.

Catela, E. Y. S; Porcile, G. (2012) "Keynesian and Schumpeterian efficiency in a BOPconstrained growth model", Journal of Post Keynesian Economics,34 (4), 777-802.

Cimoli, M.; Porcile, G. (2011) "Global growth and International Cooperation: a Structuralist Perspective",Cambridge Journal of Economics, 35 (2), 383-400.

Cimoli, M.; Porcile, G. and Rovira, S. (2010) "Structural Change and the BOP Constraint: Why did Latin America Fail to Converge?", Cambridge Journal of Economics, 34 (2), 389-411.

Chenery, H. B. e Bruno, M. (1962) "Development alternatives in an open economy: the case Israel", The Economic Journal, 72, 285, 79-103.

Christopoulos, D. K.; Tsionas, E. G. (2003) "A reassessment of balance of payments constrained growth: results from panel unit root and panel cointegration tests", International Economic Journal, 17 (3), 39-54.

Dixon, R.; Thirwall, A. (1975) "A model of regional growth-rate differences on kaldorian lines", In: J. E. King, 1994, Economic growth in theory and practice, Edward Elgar, Aldershot, n. 43.

Elliot, D.; Rhodd, R. (1999) "Explaining growth rate differences in highly indebted countries: an extension to Thirlwall and Hussain", Applied Economics, 31, 1145-1148.

Fajnzylber, R. F. (1983) "La Industrializacion Trunca de América Latina", México, Nueva Imagem. 416p.

Fajnzylber, R. F. (2000) "Da Caixa preta ao Conjunto Vazio", In: BIELSCHOWSKY, R. (org) Cinquenta Anos de Pensamento na CEPAL. Record.

Ferrari, M. A. R. (2008) "Ensaios sobre M odelos de Restrição Externa", Tese de Doutorado em economia apresentado ao Instituto de Economiada Universidade Federal do Rio de Janeiro.

Ferrari, M . A. R; Freitas, F. N. P; Barbosa-Filho, N. H. (2013) "A taxa de câmbio real e a restrição externa: uma proposta de releitura com elasticidades endógenas", Revista de Economia Política, 33 (1), 60-81.

Frenkel, R; Taylor, L. (2006) "Real exchange rate, Monetary policy and employment", DESA Working Paper, n. 19.

Frenkel, J.; Johnson, H. (1976) "The monetary approach to the balance ofpayments", London: George Allen \& Unwin.

Furtado, C. (1964) “Development and Underdevelopment”, Rio de Janeiro, Fundo de Cultura.

Furtado, C. (1974) "Teoría y política del desarrollo económico", Cidade do México: Siglo XXI.

Gabriel, L. F.; Missio, F. J.(2014) "Sistema Nacional de Inovação em um Modelo com Restrição Externa Externa", In: $42^{\circ}$ Encontro Nacional de Economia (ANPEC), 2014, Natal-RN.

Gabriel, L F.; Oreiro, J. L.; Jayme Jr., F. G. (2015) "A North-South Model of Economic Growth, Technological Gap, Structural Change and Real Exchange Rate", In: 41st Eastern Economic Association Annual Conference, New York.

Gouvêa, R. R.; Lima, G. T. (2010) "Structural change, balance-of-payments constraint, and economic growth: evidence from the multisectoral Thirlwall's law", Journal of Post Keynesian Economics, 33, 169-204.

Harrod, R. (1933) "Internacional Economics", London: CUP.

Harrod, R. (1939) "An essay in dynamic theory", The Economic J ournal, v. XLIX, n.193, march. 
Harrod, R. (1948) "Towards a dynamic economics", London: The M cM illan Press.

Harrod, R. (1973) "Dynamic Economics", London: The M cM illan Press.

Holland, M.; Vieira, F.; Canuto, O. (2004) "Economic growth and the balance-of-payments constraint in Latin America", Investigación Económica, v. LXIII, 247.

Jayme Jr., F. G. (2003) "Balance-of-payments-constrained economic growth in Brazil", Revista de Economia Política, 23 (1), 62-84.

Jayme Jr., F. G. (2007) "Growth Under External Constraints in Brazil: A Post Keynesian Approach", In: Richard Holt; Steven Pressman. (Org.). Empirical Post Keynesian Economics: Looking at the Real World. New York: M .E. Sharpe, 305-328.

Jayme Jr., F.G.; Campos, R. e Britto, G. (2014) “Endogeneity of the elasticities and the real exchange rate in a balance of payments constrained growth model: cross-country empirical evidence", Paper presented at the 19 th Conference of the Research Network Macroeconomics and Macroeconomic Policies, Berlim.

Jayme J r., F. G; Resende, M. F. C. (2009) "Crescimento econômico e restrição externa: teoria e a experiência brasileira", Rio de Janeiro: Livro IPEA, Cap. 1, 9-36.

Johansen, S. (1995) "Likelihood based inference in cointegrated vector auto-regressive models", Oxford: Oxford University Press.

Kaldor, N. (1966) "Causes of the slow rate of economic growth of the United Kingdom", Cambridge: Cambridge University Press.

Kaldor, N. (1970 [1978]) "The case for regional policies", In KALDOR, N., Futheressays on economic theory. New York: Holmes \& M eier.

Kaldor, N. (1978 [1971]) "Conflicts in national economic objectives", In Further Essays on Economic Theory. N. York: Holmes \& M eier, 155-175.

León-Ledesma, M. (2002) "Cumulative growth and the catching-up debate from a disequilibrium standpoint", In: MCCOMBIE, J.S.L. PUGNO, M. e SORO, B. (eds.) Productivity Growth and Economic Performance: Essays on Verdoorn's Law. New York: Palgrave, Macmillan.

Llerena, P.; Lorentz, A. (2004a) "Co-Evolution of Macro-Dynamics and Technological Change: an Alternative View on Growth", Revue d'économie industrielle, 105, 47-70.

Llerena, P.; Lorentz, A. (2004b) "Alternative Theories on Economic Growth and the Coevolution of Macro-Dynamics and Technological Change: A survey", LEM Working Paper Series, February.

Lopez, J.; Cruz, A. (2000) "Thirlwall's Law and beyond: the Latin American experience", Journal of Post Keynesian Economics, 22 (3), 477-495.

Marconi, N.; Araújo, E.; Oreiro, J. L. C. (2015) "The Exchange Rate, Income Elasticities and Structural Change: Theorical Foundations and Empirical Evidence", Paper presented at the 19 th Conference of the Research Network Macroeconomics and Macroeconomic Policies, Berlim.

M issio, F. J. (2012) "Câmbio e Crescimento na Abordagem Keynesiana-Estruturalista", Tese de Doutorado em Economia do Centro de Desenvolvimento e Planejamento Regional da Faculdade de Ciências Econômicas da Universidade Federal de M inas Gerais, 293 p.

M issio, F.; Jayme Jr., F. G. (2012) "Structural Heterogeneity and Endogeneity of Elasticities on the Balance of Payments Constrained Growth Model", In: Souziakis, Elias; Cerqueira, Pedro. 
(Org.). Models of Balance of Payments Constrained Growth. 1ed. London: Palgrave, 1, 239267.

Missio, F.; Jayme Jr., F. G. (2013) "Restrição Externa, Câmbio e Crescimento em um M odelo com Progresso Técnico Endógeno", Economia e Sociedade (UNICAM P. Impresso), 22 (2), 367-407.

M issio, F. J.; Araújo, R. A.; Jayme J r.; F. G. (2013) "An Extended SED Approach to BPCG: Level of the Real Exchange Rate and Endogenous Elasticities", Paper presented at the Eastern Economic Association M eetings, New York - EUA.

Missio, F. J.; Jayme Jr., F. G.; Conceição, O. A. C. (2015) "O problema das elasticidades nos modelos de crescimento com restrição externa: Contribuições ao debate", Revista de Estudos Econômicos (USP), 45, 317-346.

Moreno-Brid, J. C. (1998-99) "On capital flows and the balance-of-payments constrained growth model", Journal of Post Keynesian Economics, v. 21, n. 2, 283-98.

Moreno-Brid, J. C. (2003) "Capital flows, interest payments and the balance-of-payments constrained growth model: a theoretical and empirical analysis", Metroeconomica, 54 (2), 346-65.

M oudud, J. K. (2000) "Harrod versus Thirlwall: a reassessment of export-ledgrowth", Working paper n. 316.

McCombie, J. S. L. (1989) "Thirlwall's law and balance-of-payments-constrained growth: a comment on the debate", Applied Economics, v. 21, 9-20.

McCombie, J. S. L. (1997) "On the empirics of balance-of-payments-constrained growth", Journal of Post Keynesian Economics, 19 (3), 345-75.

McCombie, J.; Roberts, M. (2002) "The role of the balance of payments in economic growth", In Setterfield, M. (org.). The Economics of Demand Led-Growth: challenging the supply-side vision of the long run. Edward Elgar: Aldershot, 87-114.

McCombie, J.; Thirlwall, A. (1994) "Economic growth and the balance of payments constraint", New York: St. Martin's Press.

M cGregor, P. G.; Swales, J. K. (1985) “Professor Thirlwall and balance ofpayments constrained growth",Applied Economics, 17 (1), 17-32.

M yrdal, R. (1957) “Economic Theory and underdeveloped regions", London:Duckworth.

Oreiro, J. L. C.; M issio, F.; Jayme Jr., F. G. (2015) "Capital Accumulation, Structural Change and Real Exchange Rate in a Keynesian-Structuralist Growth Model", Panoeconomicus, 62, 237256.

Oreiro, J. L. C. (2016) "Inconsistency and over-determination in balance of payments constrained growth model: a note", Review of Keynesian Economics (to be publish).

Palley, T. I. (1996) "Growth theory in a Keynesian mode: some Keynesian foundations for new endogenous growth theory", Journal of Post Keynesian Economics, 19 (1), 113-135.

Palley, T. I. (2002) "Pitfalls in the theory of growth: an application to the balance-ofpaymentsconstrained growth model", in M. Setterfild (ed.), The Economics ofDemand-Led Growth: Challenging the Supply-Side Vision ofthe Long Run, Cheltenham, UK and Northampton, Ma, USA: Edward Elgar.

Pasinetti, L. (1981) "Structural change and economic growth: a theoretical essay on the dynamics of the wealth of nations", Cambridge: Cambridge University Press. 
Pasinetti, L. (1993) "Structural economic dynamics: a theory of the economic consequences of human learning", Cambridge: Cambridge University Press.

Porcile, G.; Lima, G.T. (2010) "Real exchange rate and elasticity of labour supply in a balanceof-payments-constrained macrodynamics", Cambridge Journal of Economics, 34(6), 10191039

Prebisch, R. (1949) "Introduction: The economic development of Latin America and its principal problems", Economic Survey of Latin America 1948, Santiago, Chile, ECLAC. Also published in ECLAC, Cincuenta años de pensamiento en la CEPAL: textos seleccionados, 1, Mexico City, Fondo de Cultura Económica, 1998.

Queiroz, P. W. V. D. et al. (2011) "A Lei de Thirlwall Multisetorial: um teste empírico para a economia brasileira entre 1962-2008 e uma análise da estrutura produtiva nos governos Lula", XIV Encontro de Economia da Região Sul - Anpec Sul, Santa Catarina, Junho.

Ramzi, A. Rapetti, M and Skott, P. (2012) "The real exchange rate and economic development", Structural Change and Economic Dynamics, 23, 151-169.

Resende, M. F. C.; Torres, D. R. (2008) "National Innovation System, Trade Elasticities and Economic Growth", XXXVI Encontro Nacional de Economia (ANPEC), Salvador.

Ribeiro, R. S. M., McCombie, J. S. L.and Lima, G. T. (2015) "Exchange Rate, Income Distribution and Technical Change in a Balance-of- Payments Constrained Growth Model", Department of Economics, FEA-USP, Working Paper n. 2015-01.

Rodrik, D. (2008) "The Real Exchange Rate and Economic Growth", Brooking Papers on Economic Activity, 2, 365-439.

Rowthorn, R., Ramaswamy, R. (1999) "Growth, trade and deindustrialization", IMF Staff Papers, 46 (1), 18-41.

Singer, H. S. (1950) "The distribution of gains between inventing and borrowingcountries", The American Economic Review, v.40, n. 2, 473-485.

Soares, C.; Teixeira, J. R. (2012) "A lei de Thirlwall multissetorial: novas evidências para o caso brasileiro", Encontro Nacional de Economia, Porto de Galinhas.

Thirlwall, A. P. (1979) "The Balance of Payments Constraint as an Explanation of International Growth Rate Differences", Banca Nazionale del Lavoro Quarterly Review, 128, 45-53.

Thirlwall, A. P. (1983) "Foreign trade elasticities in centre-periphery models of growth anddevelopment", Banca Nazionale del Lavoro Quarterly Review, September.

Thirlwall, A. P.; Hussain, M. (1982)

"The balance of payments constraint, capital flows and growth rates differences between developing countries", Oxford Economic Papers, 34 (3), 498-510. 


\section{Anexo 1 - Modelos de Crescimento com Restrição externa: origens teóricas, complementaridades e conflitos ${ }^{22}$.}

0 debate teórico em torno da incorporação da restrição externa como variável determinante dos limites ao crescimento econômico é bastante extenso. Conforme analisaFerrari (2008), existem diversas abordagens sobre restrição externa, sendo algumas frontalmente opostas e outras com algum grau de convergência teórica, mesmo tendo sido desenvolvidas a partir de métodos distintos e de forma independente. Destacam-se as seguintes abordagens: i) modelos export-led; i) modelos estruturalistas, baseada na abordagem Centro-periferia; ii) Modelos de Hiato (Chenery e Bruno, 1962); e iv) modelos de enfoque monetário (Frenkel e Johnson, 1976).

O Fluxograma a seguir apresenta esquematicamente algumas conexões entre aspectos das várias contribuições que culminam no modelo com restrição externa a partir das duas primeiras abordagens citadas anteriormente ${ }^{23}$. Ou seja, busca-se identificar - ao contrário do que é feito no restante do artigo - as origens teóricas que fundamentam o modelo, bem como indicar as principais contribuições que estabelecem as relações de complementariedades entre elas.

Fluxograma 1: Complementariedade e principais referências.

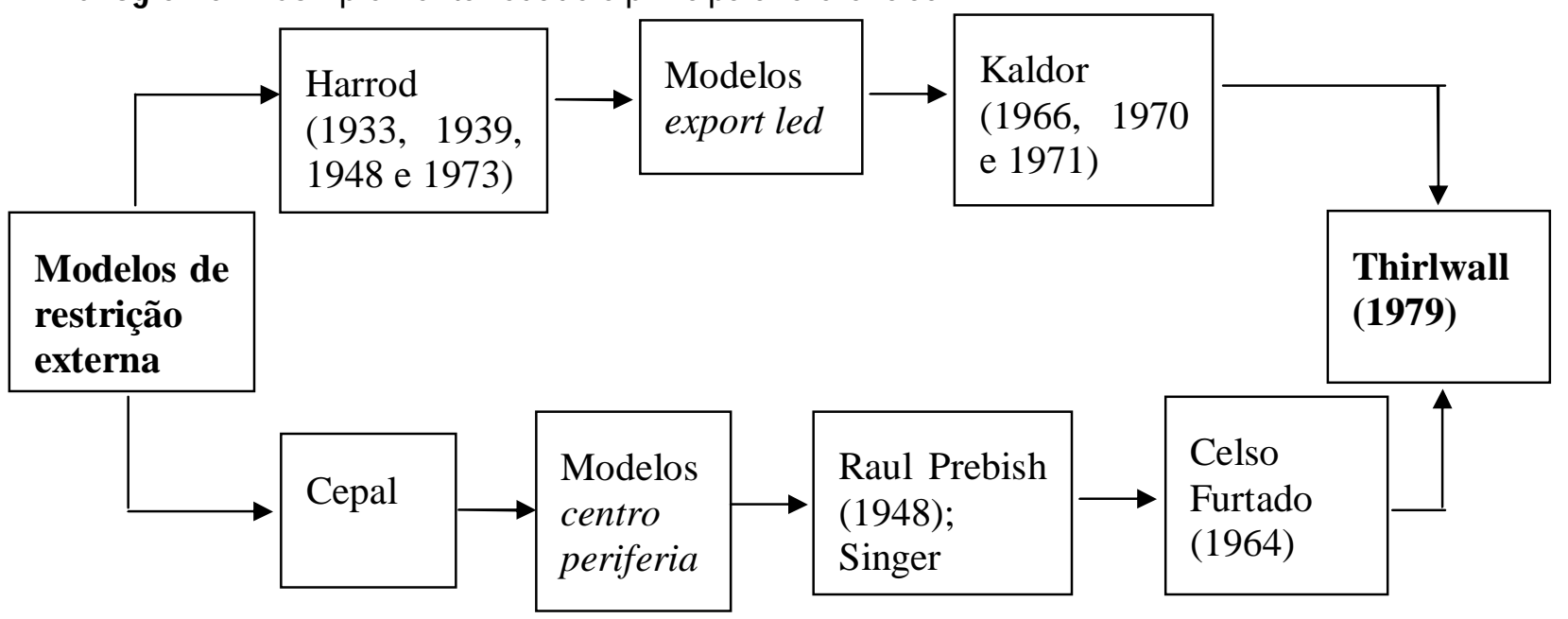

Fonte: Adaptado de Ferrari (2008).

Por um lado, a abordagem a la Thirwall tem seus fundamentos nos trabalhos de Harrod (1933), que foi o primeiro a se contrapor a abordagem clássica sobre o papel da restrição externa ao crescimento. Na visão dos economistas clássicos (derivadas de Hume, 1753) os desequilíbrios (superávit ou déficit) no fluxo de mercadorias seriam eliminados pelo fluxo oposto de metais preciosos devido à variação dos preços relativos. Ou seja, as posições superavitárias e deficitárias tenderiam a desaparecer e o sistema econômico automaticamente migraria para o equilíbrio via ajustes nos preços relativos. Assim, as condições externas não impunham nenhum limite ao crescimento.

Harrod (1933) crítica o pensamento clássico por desconsiderar o papel da restrição externa. Em sua análise sobre economia internacional (que culminou no multiplicador de comércio exterior), o equilíbrio no balanço de pagamentos, que não necessariamente

\footnotetext{
22 Baseado em Ferrari (2008).

${ }^{23}$ As outras duas abordagens não estão relacionadas aos modelos de crescimento com restrição externa a la Thirlwall (que são objeto de análise desse trabalho) e, portanto, não serão analisadas.
} 
equivalerá ao de pleno emprego, será alcançado por meio de variações no nível de atividade. 0 autor define, então, o equilíbrio no Balanço de Pagamentos (BOP) como uma restrição externa, sendo que as alterações da renda decorrentes das variações nas exportações causarão uma variação de mesma magnitude nas importações (análise estática). Em outras palavras, o autor chama a atenção para o fato de que as condições externas de uma economia importam no processo de crescimento.

No início dos anos 1970, Kaldor incorpora o multiplicador de comércio exterior de Harrod num modelo de crescimento export-led. 0 modelo é formado basicamente por quatro eixos: 1) a existência de retornos crescentes no setor produtor de bens manufaturados (Young, 1928); 2) a existência de uma relação positiva entre 0 crescimento da produtividade e 0 crescimento da produção (Verdoorn, 1949); 3) o princípio da causalidade cumulativa de Myrdal (1957); 4) o multiplicador de comércio exterior de Harrod (1933) na sua versão simplificada. 0 autor passa a defender, então, que o limite ao crescimento econômico poderia se encontrar antes do pleno emprego, ou seja, haveria uma restrição externa.

Mais especificamente, segundo Kaldor (1970), um aumento da taxa de crescimento das exportações de produtos manufaturados provocará um aumento na taxa de crescimento da produção de manufaturados e, por conseguinte, da economia como um todo; esse aumento, devido aos retornos crescentes e à Lei de Verdoorn, provocará um aumento na taxa de crescimento da produtividade; por sua vez, esse aumento irá gerar uma queda no salário de eficiência e um aumento da competitividade, proporcionando um aumento da taxa de crescimento das exportações e assim tem-se o funcionamento do princípio da causalidade cumulativa. A restrição externa ao crescimento se manifestará no equilíbrio que deverá ser mantido entre exportações e importações nesse processo de crescimento. Assim, o autor desenvolve, de maneira ainda não formalizada, o modelo de crescimento liderado pelas exportações, cuja restrição passa a ser definida pelo BOP.

Posteriormente, Thirlwall (1979) formaliza o modelo de crescimento com restrição externa. Segundo Thirwall (1983), a regra de que a taxa de crescimento de um país em relação a outros países pode ser aproximada pela razão entre a elasticidade renda da demanda por exportações e a elasticidade renda da demanda por importações, nada mais é do que 0 "multiplicador (dinâmico) do comércio internacional de Harrod"24.

Ou seja, Thirlwall (1979) representa a síntese teórica das contribuições de Harrod e Kaldor no propósito de articular uma teoria de crescimento econômico liderado pela demanda com as condições impostas pelo BOP, chegando ao que ficou conhecida como a Lei de Thirlwall, cujo status deve-se à robustez empírica do modelo teórico com os dados de vários países. De maneira geral, Thirlwall manteve a idéia de que as diferenças observadas nas taxas de crescimento entre os países eram explicadas pelo fato da demanda crescer a taxas diferentes, desempenhando as exportações o principal papel como componente da demanda agregada (crescimento liderado pelas exportações). Todavia, a principal restrição ao crescimento também se encontrava no BOP, tendo em vista a reação das importações frente ao crescimento da economia.

Cumpre ressaltar que, conforme apontou Blecker (2009), a unificação entre esse dois modelos não é trivial, ou seja, ambas as abordagens divergem significativamente em algumas de suas hipóteses. Não obstante, importantes resultados podem ser extraídos de sua combinação.

\footnotetext{
${ }^{24}$ Ver também McCombie e Thirlwall (1994, p. 237-239). Sobre as divergências entre Harrod e Thirlwall ver M oudud (2001).
} 
Por outro lado, conforme destacado por Amado e Dávila-Fernández (2015), embora tenha construído seu modelo de forma aparentemente independente, Thirlwall (1983) menciona as similaridades entre a sua formulação e a formulação estruturalista inaugurada por Prebisch (1949).

Segundo Prebish (1949), a restrição externa é fruto de questões estruturais ligadas às formas de interação comercial e financeira entre o centro industrial dinâmico (países desenvolvidos) e a periferia (economias em desenvolvimento). 0 trabalho do autor é considerado seminal para o desenvolvimento posterior das idéias cepalinas, contidas tanto nos relatórios institucionais da Cepal, coordenados em sua maioria pelo próprio Prebish, quanto nos trabalhos independentes de autores que passaram por essa instituição, entre os quais referência especial deve ser feita a Celso Furtado (1964) e Fajnzylber $(1983,2000)$.

Em síntese, sempre esteve presente na tradição estruturalista do pensamento cepalino, em algum grau, a idéia do estrangulamento externo resultante das relações de troca entre o centro e a periferia (Ver Boianovsky e Solís, 2014).

\section{Anexo 2 - Evidência Empírica}

Os testes empíricos em relação à "lei de Thirlwall" podem ser podem ser divididos em dois "momentos": no primeiro, a discussão centrou-se na identificação de formas de realização do teste e, no segundo, na técnica econométrica mais adequada (inclusão de dummies, quebra de séries, suavização de séries, escolha das variáveis relevantes, entendimento da dinâmica de ajustamento de longo e curto prazo, etc.)

a) Em relação à identificação dos testes, podem-se destacar cinco grandes linhas (Carvalho, 2005):

i) Metodologia não-paramétrica -Thirlwall (1979) buscou investigar o grau de associação existente entre a taxa de crescimento resultante do modelo teórico e a taxa de crescimento observada, para um grupo de países desenvolvidos, ao longo dos períodos compreendidos entre 1953-1976 e 1951-1973, utilizando o coeficiente de rank correlation de Spearman. Uma correlação alta entre as duas taxas de crescimento seria uma comprovação da validade do modelo;

ii) Teste de regressão - M cGregor e Swales (1985) propuseram regredir a taxa observada sobre a taxa teórica, usando uma "pooled regression" de diversos países, e testar estatisticamente as hipóteses do intercepto ser igual a zero e da declividade ser igual a um;

iii) Comparação das elasticidades de importação -McCombie (1989) propõe um teste para a comparação das elasticidades renda (hipotética e efetiva) das importações (para aplicações ver Moreno-Brid, 1998-99 e 2003; Santos, Lima e Carvalho, 2005; entre outros).A primeira etapa do teste consiste no cálculo das referidas elasticidades. A elasticidade-renda hipotética das importações $\left(\pi_{H}\right)$ é obtida a partir da "Lei de Thirwall" original (equação 5), por meio da substituição da taxa de crescimento teórica pela taxa de crescimento efetiva, ou seja, $\pi_{H}=x / y$ : Assim, a elasticidade-renda hipotética da demanda por importações é determinada pela razão entre taxa de crescimento das exportações $(x)$ e do produto $(y)$, ambos verificados no período de análise. Por outro lado, a elasticidade-renda efetiva é calculada com base na estimação da demanda por importações (a partir do log da equação 2). Por fim, testa-se a hipótese de que a elasticidade-renda das importações estimada econometricamente é igual à elasticidade-renda hipotética. A não rejeição dessa hipótese significa que não é possível rejeitar a pressuposição 
de que o crescimento do país foi restrito pelo Balanço de Pagamentos, no período estudado. De acordo com Carvalho e Lima (2009), um teste alternativo que permite aplicar esta metodologia refere-se à comparação entre a taxa de crescimento prevista pelo modelo teórico e a taxa de crescimento real. Primeiramente, estimam-se as elasticidades-preço e renda efetivas a partir de uma função importação. Em seguida, são empregadas tais estimativas para mensurar a taxa de crescimento condizente com o modelo teórico empregado. Por fim, compara-se a taxa de crescimento prevista pelo modelo teórico e a taxa de crescimento efetiva. A proximidade entre ambas as taxas valida 0 poder explicativo do modelo teórico com relação à trajetória de crescimento dos países em questão;

iv) Teste da estimação da Lei de Thirlwall -Nesse caso parte-se da estimação da própria equação de equilíbrio de conta corrente (equação 4; ou a equação 4 que incorpora o fluxo de capitais, o endividamento externo e o serviço de juros da dívida externa). Se a lei de Thirlwall for válida, espera-se que a estimativa do coeficiente dos termos de trocaseja insignificante, ou pelo menos, pouco significante com relação à estimativa do coeficiente da renda externa, $(\varepsilon / \pi)$. Para aplicações ver Jayme Jr. (2003), Lopez e Cruz (2000) e Bértola, Higachi e Porcile (2002). Segundo McCombie (1997), a principal desvantagem desse procedimento reside no fato de estar testando se 0 Balanço de Pagamentos se encontra em equilíbrio, essencialmente, a cada instante de tempo, isto é, no curto prazo.

v) Análise de ajustamento da conta corrente -concebida por Alonso e Garcimartín (19981999), o objetivo é investigar qual o impacto exercido pelas alterações de renda ou de preço sobre os desequilíbrios da conta corrente. Para tanto, os autores estimam um sistema de equações especificando uma equação que reflete a alteração da renda e outra a variação dos preços relativos, ambas em decorrência de um déficit externo e de uma discrepância entre o preço doméstico e o preço estrangeiro. Assim, se na primeira equação o coeficiente for estatisticamente diferente de zero validará a Lei de Thirlwall, sugerindo, portanto, que a variação da renda é responsável por uma parte do ajustamento do BOP. Carvalho e Lima (2008) sugerem a estimação de uma versão completa da equação 4, por meio da inclusão do componente financeiro na condição de equilíbrio do setor externo, em termos tanto de influxo de capitais como de serviços de fatores. Assim, empregando-se a metodologia de Johansen (1995) para a estimação, obtém-se, por um lado, através do vetor de cointegração, a relação de equilíbrio de longo prazo entre as variáveis de interesse e, por outro, os coeficientes de ajustamento possibilitam as variáveis que se ajustam no curto prazo para gerar o equilíbrio de longo prazo do BOP. Portanto, de acordo com a metodologia acima detalhada, a estimação direta de uma versão completa da condição de equilíbrio do BOP através de técnicas de cointegração, possibilita a combinação de duas linhas de testes empíricos (o teste da estimação da lei de Thirlwall em si e o teste de análise de ajustamento da conta corrente).

b) Em relação às técnicas econométricas utilizadas, destacam-se resumidamente as seguintes estratégias empíricas:

vi) As primeiras estimativas das elasticidades-preço e renda da demanda por importações e exportações (log das equações 1 e 2; variáveis em nível) ou mesmo da equação 
de equilíbrio do Balanço de Pagamentos (variáveis escritas como taxa de variação - ver Atesoglu, 1993) utilizaram a técnica do M ínimos Quadrados Ordinários;

vii) Posteriormente, testes mostraram que a maioria das séries envolvidas eram não estacionárias. Portanto, as funções deveriam ser estimadas em primeira diferença (Bairam, 1993);

viii) 0 uso de primeiras diferenças, embora resolva o problema da regressão espúria, perde informação de longo prazo da série. Assim, a estimativa mais correta é utilizar variáveis em logaritmo do nível, utilizando o instrumental de cointegração. Em outras palavras, utiliza-se a metodologia de Johansen.

ix) Recentemente, tem-se utilizado a metodologia de dados em painel. Por exemplo, Christopoulos (2003) utilizou a metodologia de cointegração em painel (realizou um teste de raiz unitária em painel para verificar a ordem de integração das séries e, em seguida, estimou os vetores de cointegração através do Fully M odified OLS técnica para painéis heterogêneos cointegrados). Ver também Cimoli, Porcile e Rovira(2010), entre outros. 